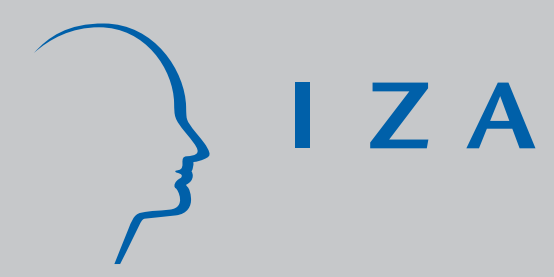

IZA DP No. 3708

Race, Ethnicity and the Dynamics of Health Insurance Coverage

Robert W. Fairlie

Rebecca A. London

September 2008 


\title{
Race, Ethnicity and the Dynamics of Health Insurance Coverage
}

\author{
Robert W. Fairlie \\ University of California, Santa Cruz, \\ RAND and IZA \\ Rebecca A. London \\ Stanford University
}

\section{Discussion Paper No. 3708 \\ September 2008}

\author{
IZA \\ P.O. Box 7240 \\ 53072 Bonn \\ Germany \\ Phone: +49-228-3894-0 \\ Fax: +49-228-3894-180 \\ E-mail: iza@iza.org
}

\begin{abstract}
Any opinions expressed here are those of the author(s) and not those of IZA. Research published in this series may include views on policy, but the institute itself takes no institutional policy positions.

The Institute for the Study of Labor (IZA) in Bonn is a local and virtual international research center and a place of communication between science, politics and business. IZA is an independent nonprofit organization supported by Deutsche Post World Net. The center is associated with the University of Bonn and offers a stimulating research environment through its international network, workshops and conferences, data service, project support, research visits and doctoral program. IZA engages in (i) original and internationally competitive research in all fields of labor economics, (ii) development of policy concepts, and (iii) dissemination of research results and concepts to the interested public.
\end{abstract}

IZA Discussion Papers often represent preliminary work and are circulated to encourage discussion. Citation of such a paper should account for its provisional character. A revised version may be available directly from the author. 


\section{ABSTRACT}

\section{Race, Ethnicity and the Dynamics of Health Insurance Coverage}

Using matched data from the 1996 to 2004 Current Population Survey (CPS), we examine racial patterns in annual transitions into and out of health insurance coverage. We first decompose racial differences in static health insurance coverage rates into group differences in transition rates into and out of health insurance coverage. The low rate of health insurance coverage among African-Americans is due almost entirely to higher annual rates of losing health insurance than whites. Among the uninsured, African-Americans have similar rates of gaining health insurance in the following year as whites. Estimates from the matched CPS also indicate that the lower rate of health insurance coverage among Asians is almost entirely accounted for by a relatively high rate of losing health insurance. In contrast to these findings, differences in health insurance coverage between Latinos and whites are due to group differences in both the rate of health insurance loss and gain. Using logit regression estimates, we also calculate non-linear decompositions for the racial gaps in health insurance loss and gain. We find that two main factors are responsible for differences in health insurance loss between working-age whites and minorities: job loss and education level. Higher rates of job loss account for 30 percent of the health insurance gap for AfricanAmericans and Asians, and 16 percent of the health insurance gap for Latinos. Lower levels of education explain roughly 15 percent of the gap for African-Americans and Latinos (Asians' higher levels of education serve to close the gap). Higher rates of welfare and SSI participation among African-Americans also serve to widen the gap in health insurance loss by 8 percent.

JEL Classification: I1, J15

Keywords: race, health insurance, insurance dynamics

Corresponding author:

Robert W. Fairlie

Department of Economics

University of California

Engineering 2 Building

Santa Cruz, CA 95064

USA

E-mail: rfairlie@ucsc.edu

\footnotetext{
* The Employment Policies Institute and the U.S. Department of Labor provided funds for this research. The views expressed here are solely the responsibility of the authors and should not be interpreted as reflecting the views of the Employment Policies Institute or the U.S. Department of Labor. We would like to thank Carlos Dobkin, Craig Garthwaite, John Holohan, Matt Rutledge, Donald Wittman, participants at the 2005 Annual Meetings of the Association for Public Policy Analysis and Management and the Economic Research Initiative on the Uninsured Workshop on Health Insurance Transitions at the University of Michigan for useful comments and suggestions. Oded Gurantz provided excellent research assistance.
} 


\section{Introduction}

In 2004, 45.8 million people, or 16 percent of the U.S. population, lacked health insurance. Trends indicate that both the number and rate of uninsurance have increased since the late 1980s (DeNasvas-Walt, Proctor, and Lee 2005). Minorities are especially vulnerable, with strikingly low rates of health insurance coverage in the United States. Nearly 20 percent of African-Americans and Asians and 33 percent of Latinos do not have health insurance, compared to only 11 percent of white, nonLatinos (U.S. Bureau of the Census 2004). These racial and ethnic disparities in health insurance coverage have persisted over the past decade (U.S. Bureau of the Census 1995, 2004).

Previous research indicates that family income, job characteristics and nativity are important factors in explaining why minorities have lower rates of coverage (see Pollack and Kronebusch 2002 and Crow, Harrington, and McLaughlin 2002 for recent reviews of the literature), but very little research focuses on the dynamic patterns of health insurance coverage by race and ethnicity. For example, the basic question of whether the low rates of coverage among minorities are due to high rates of insurance loss, low rates of gaining insurance, or a combination of the two is not known. The extent to which racial differences in health insurance transitions are related to group differences in job loss and changes in employer types is also unknown. The literature has focused primarily on racial patterns in point-intime insurance coverage, which may mask important differences in rates of health insurance transitions. An analysis of the dynamics of health insurance coverage is preferable for studying racial patterns because it provides insights into the underlying causes of lower rates of insurance coverage. For example, estimates reported later in this paper indicate that African-Americans are less likely to be insured than are whites because they are more likely to lose health insurance than whites and not because they are less likely to gain health insurance. 
Understanding the racial patterns in the dynamics of health insurance is important because of its implications for continuous coverage. Many of the uninsured at a point in time are in fact intermittently covered, and this intermittent coverage appears to be much less beneficial than continuous coverage resulting in outcomes that more closely resemble the outcomes of the continuously uninsured (Baker et al. 2001). Intermittent coverage has been shown to result in use of fewer preventive health services (Sudano and Baker 2003) and increased problems in accessing medical care and following up on this care (Schoen and DesRoches 2000). Previously uninsured or intermittently insured adults who gain access to health insurance tend to show improvements in their use of medical services, although it may take several years for this to occur (Sudano and Baker 2003; McWilliams et al. 2003).

Given these concerns, it is surprising that relatively few previous studies focus on dynamic patterns of health insurance coverage. Examining point-in-time insurance coverage may mask large movements into and out of insurance. Exploring both types of transitions may be especially important for understanding the causes of ethnic and racial differences in health insurance coverage. In this study, we examine racial patterns in annual transitions into and out of health insurance coverage using matched data from the 1996 to 2004 Current Population Survey (CPS). Although the CPS has primarily been used as cross-sectional samples, we create a two-year panel by linking consecutive surveys. The large sample sizes and panel data in the matched CPS allow us to explore the health insurance consequences of racial differences in very detailed employment and job characteristics as well as demographic characteristics. To our knowledge, the matched CPS data have not been previously used to explore racial differences in health insurance transitions. The two-year CPS panel is especially useful for examining the basic question of whether health insurance coverage differentials between whites, African-Americans, Latinos and Asians are due to high rates of health insurance loss, low rates of obtaining health insurance, or both. 
Using the matched CPS data, we examine whether dynamic factors, such as job loss, change in employer types, movement from a large employer to a small employer and other changes in job characteristics are associated with health insurance loss. We also explore whether changes in employment and job characteristics are associated with gaining health insurance. Although it is difficult to identify causal factors of health insurance transitions, the analysis of the relationship between changes in health insurance coverage and changes in potentially correlated factors using the large two-year panel data in the CPS improves on cross-sectional analyses and offers some of the first estimates of the relationship between changes in very detailed employment and job characteristics and changes in health insurance coverage.

After identifying the causes of transitions in health insurance coverage, we use the estimates to explore the causes of racial differences in health insurance coverage. We use a special nonlinear decomposition technique to identify which changes in employment and job characteristics that are associated with losing and gaining health insurance are responsible for racial differences in health insurance transitions. We examine the relative importance of these factors in contributing to racial gaps in health insurance loss and health insurance gain, and how much of the racial differences in transition rates can be explained by these factors.

\section{Previous Literature on Health Insurance Dynamics}

The literature on health insurance dynamics emphasizes that a dynamic approach to studying health insurance coverage represents an improvement over point-in-time analyses. If spells of uninsurance are short and end with regained insurance coverage, we might be less concerned about lack of health insurance. If, however, those who are uninsured remain uninsured for long periods or repeatedly gain and lose insurance, we might be more concerned about the well-being of the uninsured. 
Studies of health insurance dynamics have focused mostly on the duration of uninsurance spells and the characteristics of individuals with longer spells. One of the pioneering studies in this area found that half of uninsurance spells end within four months, and 15 percent last more than two years (Swartz and McBride 1990). More recent data published by the Congressional Budget Office indicate an increase in the share with longer spells— -41 percent of uninsurance spells lasted less than four months and 18 percent lasted more than two years (CBO 2003). Taking a slightly longer time perspective, Short and Graefe (2003) find that over a four-year period, one out of three working-age adults have a lapse in coverage. Poor, less educated, and Latino families are more likely than others to have longer uninsurance spells (CBO 2003; Zuckerman and Haley 2004). Forty-two percent of the uninsured have incomes less than 150 percent of the federal poverty line and have been uninsured for more than a year (McBride 1997). Data from the Medical Expenditure Panel Survey (MEPS) indicate that 30 percent of individuals who are uninsured re-gain insurance in the subsequent year (Monheit, Vistnes, and Zuvekas 2001). Certain factors lead to higher probabilities of regaining insurance, including higher educational attainment, non-poverty family income, and prior employment in certain industries (Swartz, Marcotte, and McBride 1993).

Very few studies focus on dynamic factors that are associated with health insurance transitions. An exception is Czajka and Olsen (2000), who study "trigger events" for children’s health insurance transitions using the SIPP. They examine several potential "triggers" of changes in health insurance coverage, including changes in family economic situations and composition. They find that when a parent loses a job, experiences an hours worked reduction, or changes jobs, children are more likely to lose employer-sponsored health insurance and become uninsured. Decreases in family income and family size are also found to be associated with insurance loss. The findings are less clear for factors associated with children gaining health insurance, but increases in parental hours worked, family income 
and parents in the family appear to be associated with becoming insured. Of course, these factors may be endogenous and the authors do not argue that they should be viewed as exogenous factors affecting health insurance transitions.

The findings from the previous literature point to the importance of studying health insurance dynamics, however, previous studies have not examined in detail the employment and job characteristics associated with individuals who gain and lose health insurance. Our study contributes to the literature by identifying numerous potential trigger events associated with health insurance gain and loss for adults, such as changes in employment, employer size, employer type, hours and weeks worked, spousal employment, marital status, presence of children, and receipt of public assistance. This research also adds to the literature in that we model both sides of the transition: gain and loss of health insurance. The large sample sizes available in the CPS are especially important for identifying factors associated with gaining health insurance because the analysis relies on the uninsured sample in the first survey year.

In previous research, we examine whether changes in detailed employment and job characteristics are associated with gaining and losing health insurance (Fairlie and London 2005). We find numerous potential trigger events that are associated with health insurance gain and loss, such as changes in employment, employer size, employer type, hours and weeks worked, spousal employment, marital status, presence of children, and receipt of public assistance. We also find that changes in employment and job characteristics do not have symmetrical relationships with losing and gaining insurance. For example, we find that job loss is more strongly associated with losing health insurance than the association between finding a job and gaining health insurance.

Our own previous work and the literature in general have identified certain risk factors associated with uninsurance, one of which is minority status. However, the literature on racial differences in health insurance dynamics is limited. We build on our previous research, the findings 
from the literature on health insurance dynamics, and the literature on racial differences in health insurance to provide an analysis of the causes of racial differences in the dynamics of health insurance coverage. The large sample sizes available in the CPS are especially important for studying blacks, Latinos and Asians, and for identifying factors associated with gaining health insurance because the analysis relies on the uninsured sample in the first survey year.

\section{Data}

We use data from the 1996 to 2004 Annual Demographic and Income Surveys (March) of the Current Population Survey (CPS). The survey, conducted by the U.S. Census Bureau and the Bureau of Labor Statistics, is representative of the entire U.S. population and interviews approximately 50,000 households and more than 130,000 people. It contains detailed information on health insurance coverage, employment, demographic characteristics and income sources. We limit the sample to working age adults, ages 25-55 to avoid problems associated with including young adults who are in school and older adults who retire-groups who we expect to have a weaker attachment to the labor force.

Although the CPS is primarily used as a cross-sectional dataset offering a point-in-time snapshot, it is becoming increasingly common to follow individuals for two consecutive years by linking surveys. Households in the CPS are interviewed each month over a 4-month period. Eight months later they are re-interviewed in each month of a second 4-month period. The rotation pattern of the CPS makes it possible to match information on individuals in March of one year who are in their first 4-month rotation period to information from March of the following year, which represents their second 4-month rotation period. This creates a one-year panel for up to half of all respondents in the first survey. To match these data, we use the same criteria as Madrian and Lefgren (2000) for matching the CPS March files from 
1996 to 2000, but use modified criteria for the 2001 to 2004 data. ${ }^{1}$ Across, the 1996-2004 CPS surveys, we find that roughly 75 percent of CPS respondents in one survey can be identified in the subsequent year's survey.

Using the matched CPS, we can identify changes in an individual's health insurance status, as well as in employment, hours worked and employer size. One drawback to these data is that when respondents leave a particular household they are not followed to their next household. A consequence of this is that when households dissolve due to marital breakup, the CPS does not re-interview both marital partners. ${ }^{2}$ We are therefore unable to reliably examine insurance gain and loss due to marital status changes, and focus instead on gain and loss due to changes in employment characteristics. We can, however, examine the relationship between spousal job changes and health insurance transitions for adults whose marriages remain intact.

The health insurance variables used for this analysis refer to the respondent's health insurance in the year prior to the March survey. The transition therefore identifies changes in coverage people experience over the course of one year to what they experience over the course of the next year. We rely on labor market variables that cover the same time period. The transitions can therefore be thought of as covering two full years, the 12 months prior to the first survey year and the 12 months prior to the second survey year. Thus, in our health insurance loss analysis, we examine movement between having insurance for any part of the first survey year and not having insurance for the entire second survey year.

The percent of individuals who report not having insurance over the previous year provides an estimate of the percent of individuals who are currently experiencing an uninsurance spell of at least one

\footnotetext{
${ }^{1}$ Prior to matching years, we remove the supplemental samples to the 2001 to 2004 ADFs, which are generally not reinterviewed in the following March.

${ }^{2}$ Another consequence is that the matched data are not a representative sample of the original CPS sample. We find comparing sample means, however, that the matched sample is only slightly older, higher income, more educated, more insured, and less likely to be a minority than the original sample. Although the matched sample represents a slightly more advantaged and stable population than the original sample, the focus here on ethnic and racial differences should be less affected.
} 
year. We can also estimate the percent of individuals who are currently experiencing an uninsurance spell of at least two years by examining the percent of individuals who were uninsured in the first survey year and the second survey year. Estimates from our matched CPS sample indicate that 15 and 8 percent of adults are currently experiencing an uninsured spell of at least 1 and 2 years, respectively. Although not directly comparable, estimates from the SIPP indicate that approximately 13 percent of individuals are currently experiencing an uninsured spell of more than 12 months (CBO 2003).

Comparisons of estimates of health insurance coverage using the CPS and other datasets that include a point-in-time measure of health insurance reveal similar numbers of uninsured individuals. Estimates from the Survey of Income and Program Participation (SIPP), Medical Expenditure Panel Survey (MEPS) and National Health Interview Survey (NHIS) indicate that roughly 40 million individuals are uninsured at the time of the survey in 1998 (CBO 2003). Estimates from the CPS for the number of individuals with no insurance for the entire year are also roughly 40 million, suggesting that the CPS overstates the number of individuals who are uninsured over the entire year. Indeed, estimates from SIPP and MEPS, which also include multiple observations over the year, indicate that 21.1 and 31.1 million people are uninsured for the entire year, respectively. Bhandari (2004) finds similar estimates of insurance coverage rates in the CPS and point-in-time estimates from the SIPP even within several demographic groups. Thus, CPS respondents may be underreporting health insurance coverage over the previous calendar year because of recall bias or because they simply report their current coverage (see Bennefield 1996, Swartz 1986, CBO 2003, and Bhandari 2004 for further discussion). Even if the CPS estimates capture a point-in-time measure of health insurance coverage, the measure of health insurance status does not change from year to year and thus allows for an analysis of transitions in status. However, this would alter the interpretation of our results. In our interpretation, we assume that respondents interpret the question correctly. 


\section{Racial Differences in Health Insurance Transitions}

Table 1 reports health insurance coverage and transition rates using the CPS sample. The coverage rates measure health insurance at any point in the previous year, and capture all types of health insurance coverage. The sample sizes in the CPS are large enough even within racial groups that we can limit the sample to adults ages 25-55. By focusing on working-age adults we avoid problems associated with including young adults who are in school and older adults who retire-groups who we expect to have a weaker attachment to the labor force.

In total, 85.6 percent of adults in the CPS sample have health insurance in the reference year, which we refer to as the first survey year or year t. Among the 14.4 percent of individuals without insurance in the first survey year, column 2 shows that 46.2 percent gain insurance in the subsequent year. For those who are insured in year t, column 3 reports that 7.5 percent lose coverage in the subsequent year.

Examining health insurance patterns by race and ethnicity, we find that the health insurance coverage rate for African Americans is 80.5 percent, compared to 89.2 percent for white, non-Latinos. Latinos have even lower rates of coverage at 66.9 percent. Asians also have a lower rate of health insurance coverage than whites at 81.5 percent. These racial patterns are well known and have been documented extensively in the literature (see Crow, Harrington, and McLaughlin 2002 for example). What is less known, however, is whether there exist large racial differences in transition rates into and out of health insurance coverage. This type of analysis requires a large enough sample size and panel data.

Estimates from the matched CPS indicate that there also exist large racial differences in health insurance coverage transitions. African-Americans have double the rate of insurance loss relative to 
whites (11.7 percent compared to 5.8 percent) over the entire period, but comparable rates of gaining health insurance. Latinos have both a lower rate of health insurance gain (33.3 percent compared to 50.4 percent for whites) and a higher rate of health insurance loss (16.3 percent compared to 5.8 percent for whites). More similar to blacks, Asians have a high rate of health insurance loss (10.5 percent), but a rate of health insurance gain that is comparable to whites. Estimates of health insurance transitions by year also indicate similar racial patterns over the entire sample period (see Figures 1 and 2).

A simple decomposition of the transition rate into and out of health insurance coverage can be performed to quantify the contributions of racial differences in health insurance loss and racial differences in health insurance gain to the racial gaps in health insurance coverage. To perform this decomposition we first note that the steady-state health insurance coverage rate in a simple model of two labor market states is equal to $\mathrm{g} /(\mathrm{g}+\mathrm{l})$, where $\mathrm{g}$ is the rate of gaining health insurance and $\mathrm{l}$ is the rate of losing health insurance. We then simulate steady-state health insurance coverage rates for alternative combinations of health insurance gain and loss rates by race. Estimates of these simulations are reported in Table 2.

The steady-state rate of health insurance coverage for blacks is 80.8 percent which is very close to the actual rate of 80.5 percent. The estimated steady-state rate of health insurance coverage is 89.6 percent for whites, implying a black/white gap in coverage of 8.8 percentage points. If blacks are given the much lower rate of health insurance loss for whites, the black health insurance coverage rate increases from 80.8 percent to 89.4 percent, which represents nearly the entire gap in coverage rates. On the other hand, if blacks are given the white rate of insurance gain, the estimated steady-state coverage rate only increases from 80.8 percent to 81.2 percent or 0.4 percentage points. Similar estimates are derived from starting with the white steady-state rate of health insurance coverage and simulating what would happen by switching in the black rate of health insurance gain or the black rate of health 
insurance loss. The simulations indicate that 96 to 97 percent of the black/white gap in health insurance coverage rates is due to the relatively high rate of losing health insurance for blacks.

Table 2 also reports estimates for the decomposition for Latinos. In contrast to the findings for the black/white difference in health insurance coverage, the Latino/white difference is due to group differences in both the rate of health insurance loss and gain. The higher rate of health insurance loss among Latinos relative to whites is responsible for 63 to 80 percent of the gap in health insurance coverage rates. The lower rate of health insurance gain among Latinos accounts for the remaining 20 to 37 percent of the Latino/white difference at a point in time.

Perhaps due to small sample sizes in many other datasets, the low rates of health insurance coverage among Asians have not been carefully studied. The CPS findings for Asians are similar to those for blacks. Almost the entire Asian/white gap in health insurance coverage rates is accounted for by the relatively high rate of losing health insurance among Asians. Although Asians and blacks have similar loss rates, we speculate that the underlying causes of health insurance loss may differ greatly between the two groups.

An examination of transitions into and out of coverage clearly provides a more complete understanding of the reasons that some groups have higher and lower rates of uninsurance. Exploring the potential causes of racial differences in transitions into and out of health insurance coverage separately may be similarly revealing. To our knowledge, these patterns have not been previously documented.

\section{Identifying Dynamic Factors Correlated with Health Insurance Loss}

Before examining the causes of racial differences in health insurance transition rates, we need to first identify the dynamic factors associated with insurance loss and gain. Once we identify these factors 
for the total insured and uninsured populations then we can explore whether these factors explain racial differences in health insurance coverage.

What are the causes of health insurance loss and gain? Although it is well known that identifying causal relationships in the health insurance literature represents a difficult task (see Chernew and Hirth 2002 for a discussion of the issues), an analysis of correlated dynamic factors may be informative. For example, job loss or gain, moving between full-time and part-time employment, and employment size changes represent dynamic factors that could potentially trigger a change in health insurance coverage. ${ }^{3}$ The fundamental problem is that preferences for health insurance coverage are likely to inform employment decisions, and thus changes in employment characteristics may be caused by changes in health care insurance needs. The inability to measure preferences or potential demand for health insurance or find a good proxy suggests that we need to be careful in interpreting the results.

Before turning to estimates from multivariate regressions, we first examine the relationship between changes in job characteristics and loss of health insurance. Tables 3 and 4 present tabulations of health insurance loss and gain by employment status and characteristics at both year $t$ and year $t+1$. To place some structure on the presentation of these results we focus on a limited set of changes instead of the numerous possible combinations of changes in job characteristics.

Table 3 reports matrices of health insurance loss and gain by employment status in year $t$ and year $\mathrm{t}+1$. The loss transition matrix shows, for example, that not having a job in both survey years is associated with a 9.3 percent loss in health insurance. Continued employment over the two year period (though perhaps not at the same job) is associated with a 6.6 percent loss in insurance. Mobility between the two states is associated with health insurance loss at much higher rates. For instance, movement from a job in year $\mathrm{t}$ to no job in year $\mathrm{t}+1$ is associated with a 19.9 percent decline in health

\footnotetext{
${ }^{3}$ Similar to Czajka and Olsen (2000) we view these dynamic factors as "trigger events" instead of as truly exogenous determinants of health insurance transitions.
} 
insurance. These results suggest that job loss is a key contributor to health insurance loss. Movement from no job in year t to a job in year $\mathrm{t}+1$, however, is also associated with a large loss of health insurance at 16.0 percent. This may be the result of waiting periods associated with gaining health insurance, loss of government-provided insurance, or other characteristics of the jobs into which individuals are moving.

There is far less contrast in the health insurance gain model across the four cells. Movement from either employment state in year $t$ to no job in year $t+1$ is associated with a 41 to 42 percent gain in insurance. Movement from either state into a job in year $t+1$ is associated with slightly higher rates of insurance gain, particularly if one is employed in both periods.

To explore this further, we present comparable transition matrices by employment characteristics among those who were employed in both years $t$ and $t+1$. Table 4 shows the transition matrix by employer size. Employer size appears to be strongly associated with both gaining and losing health insurance. Movement from any employer size into the smallest size (1-9 employees) is associated with the highest rates of insurance loss and the lowest rates of insurance gain. Insurance loss rates decline and gain rates increase as employer size increases. These results are consistent with employer size being an important determinant of health insurance transitions.

\section{HEALTH INSURANCE LOSS REGRESSIONS}

The estimates reported in Tables 3 and 4 point to the importance of examining changes in employment characteristics in understanding the reasons that individuals lose or gain health insurance coverage. It is likely, however, that many of the dynamic employment characteristics are correlated. For example, moving from a government employer to private employer and large employer to small employer are both correlated with health insurance loss, and are likely to correlated with each other. To 
identify independent relationships, we estimate probit regressions for annual health insurance transitions. We are reluctant to identify these as causal factors because employment choices may be made to facilitate preferred health insurance status. We instead view them as "trigger events" or dynamic factors that are associated with health insurance loss, though they are theoretically likely to have strong causal effects on health insurance loss. The dynamic factors that we include are changes in employment, full-time, full-year status, employment size, type of employer, presence of children, martial status, spousal employment, welfare receipt and Supplemental Security Income (SSI) receipt. ${ }^{4}$

Specification 1 of Table 5 reports estimates for our base probit regression for the probability of losing health insurance. ${ }^{5}$ We do not focus on racial differences here and postpone this discussion to the next section. Our goal here is to identify the dynamic factors associated with health insurance loss for the total insured population. Changes in one's own employment and job characteristics are strongly associated with health insurance loss. We first discuss the results for the four possible transitions between employment and non-employment status. The reference category is having a job in both years. Non-employment in both years is associated with a 5.3 percentage point higher probability of losing health insurance relative to having a job in both years. This may be due to length of time without a job and the 18-month period of COBRA binding.

Job loss has the strongest relationship with health insurance loss. Workers who lose their jobs have a 12.1 percentage point higher likelihood of losing heath insurance coverage than workers who remain employed. The estimated relationship is strong and even larger than the mean rate of health insurance loss in the sample (7.2 percent). Although we cannot determine causality, the strength of the relationship suggests that job loss triggers many people to lose coverage.

\footnotetext{
${ }^{4}$ We also include year fixed effects to control for unobservable or difficult to measure policies, prices and other factors that may change over time.

${ }^{5}$ We also estimate probit regressions for the probability of losing private health insurance. We find similar results for most variables. The main exceptions are that the association between loss of welfare or SSI is weaker for private health insurance loss than it is for any health insurance loss.
} 
We also find that individuals who are not employed in the first year but become employed in the second year are more likely to lose health insurance than are individuals who are employed in both years. The relationship may be due to a higher rate of job instability among this group, the types of jobs performed by people with unstable jobs, or waiting periods to start new employer coverage.

The strong relationship between employer size and health insurance coverage is demonstrated in the multivariate analysis. Workers who move down our broad employment size categories are 4.3 percentage points more likely to lose health insurance than are workers who do not change employer size. Workers who move up a category in employment size have a higher likelihood of losing health insurance than workers who do not change employer size, but the relationship is not strong. This may be due to employer changes that are not captured in our measure of job change. ${ }^{6}$

Movement from a private employer to self-employment is also associated with health insurance loss, net of other trigger events. Workers who move from private firms to self-employment are 4.2 percentage points more likely to lose health insurance than are workers who do not change employer types. Movement from government employment to self-employment is associated with an even larger loss of health insurance of 5.3 percent. Finally, movement from government employment to private employment is not associated with a statistically significant higher probability of losing health insurance. The relationship between employment type and health insurance loss holds even after controlling for changes in employer size.

Any type of employer change is associated with the loss of health insurance; workers moving to a new employer from the first survey year to the following survey year are 3.6 percentage points more likely to lose health insurance than workers who do not change employers. Although our approximation

\footnotetext{
${ }^{6}$ The CPS does not include a direct measure of employer changes. We impute employer changes from employer type, employer size, and major industry category changes and multiple jobs in the second survey year. We find that 38.9 percent of the sample has an employer change using our imputed measure, which likely to overstate employer changes (see Fairlie and London 2005 for more discussion).
} 
of employment change is not perfect, it does appear to capture job changes that are associated with losing health insurance.

We include dummy variables indicating whether the individual loses welfare or SSI, both of which confer almost universal Medicaid eligibility, from the first year to the following year. Welfare loss is associated with a 9.6 percentage point higher probability of losing health insurance, and SSI loss is associated with a 6.4 percentage point higher probability of losing health insurance.

Focusing on dynamic demographic factors, we do not find evidence that individuals lose health insurance when children leave the household. Instead, movement of children out of the household is associated with a lower rate of health insurance loss. As one might expect, divorce appears to be correlated with losing health insurance. As noted above, however, the matched CPS are not ideal for studying the effects of changes in marital status on health insurance because individuals who move from the original household are not followed in the CPS.

Conditioning on being married in both years, we find evidence that the loss of a spouse's job is associated with health insurance loss. Individuals who have a spouse who lost his or her job are 4.7 percentage points more likely to lose health insurance. This loss is most likely due to losing coverage under the spouse, but also could be due to the resulting loss of income.

Specifications 2-4 of Table 5 report estimates for more detailed sets of employment characteristics. Specification 2 adds dummy variables measuring several changes between full-time and part-time, and full-year and part-year status. Specification 3 adds these and also more detailed employer firm size changes. Specification 4 also adds demographic controls that do not change over time. Although these cannot trigger health insurance loss, they may be correlated with our dynamic factors. We include controls for sex, race/ethnicity, immigrant status, marital status, number of children, education, age, disability, veteran status, region, urbanicity and year effects. The results across 
specifications are very similar. For brevity, we focus on Specification 3 findings for the total insured population.

Focusing first on the more detailed employment commitment variables, we find that any movement that reduces hours per week (full-time to part-time) or weeks per year (full-year to part-year) is associated with a higher probability of health insurance loss. The reference category is workers who do not change hours and weeks worked across our categories, which represents 68.1 percent of insured adults. Workers who lose full-time, full-year jobs have the highest probability of losing health insurance. They are 16.3 percentage points more likely to lose health insurance than are workers who remain employed and do not change statuses. Movement from full-time, full-year work to either partyear work or to part-time work is also associated with a high level of health insurance loss. Full-time, full-year workers who become employed only part year are 5.0 percentage points more likely to lose health insurance, and full-time, full-year workers who become employed only part time are 5.7 percentage points more likely to lose health insurance. Evidently, movement to part-time or part-year status is related to losing health insurance even after controlling for other changes in job characteristics. These estimates suggest that the effects of this movement are likely to be large.

Using the large sample sizes of the CPS, we can also examine the relationship between movement between additional hours and weeks worked categories. We find that movement from parttime, full-year work to non-employment is associated with a very large probability of losing health insurance of 9.7 percentage points, relative to workers who do not change statuses. Part-year workers who lose their jobs also have a high rate of insurance loss; they are 11.0 percentage points more likely to lose coverage. Part-time, full-year workers who switch to part-year work experience a relatively high level of health insurance loss, although not as large as the previous two groups. 
Our findings point to a strong relationship between time commitment on a job and health insurance loss. We cannot identify the causal effect, but these results are clearly consistent with idea that reducing work commitment can result in loss of health insurance. The estimates also emphasize the importance of job loss in determining health insurance loss, especially for full-time, full-year workers.

Returning to employer size, we are particularly interested in examining whether there are differential relationships when moving one category in employment size or moving more than one category in employment size. The reference category for this set of variables is workers who do not change employer size. We define large firms as those with 100 or more employees, medium firms as those with 25-99 employees, small firms as those with 10-24 employees, and very small firms at those with 1-9 employees.

Movement from large firms to any other size employer is associated with health insurance loss and the magnitude of the loss is larger as the resulting employer size decreases. Workers at large firms who switch to medium size firms are 3.0 percentage points more likely to lose health insurance than workers who do not change employer size. Workers at large firms who switch to small firms are 6.6 percentage points more likely to lose health insurance and workers at large firms who switch to very small firms are 8.0 percentage points more likely to lose health insurance. We also find that movement from medium size firms to smaller firms is associated with a high probability of losing health insurance and the size of the loss is larger when the movement is to a firm with 1-9 employees instead of 10-24 employees. Finally, we find that movement from a small employer to a very small employer is associated with a higher probability of losing health insurance. Overall, these estimates clearly indicate that downward movement in employer size is associated with health insurance loss and the magnitude of this loss is related to size of the change in employer size. It is also useful to note that these findings hold 
even after controlling for changes in type of employer (e.g. government employment to private employment or self-employment).

Although not reported, in Specification 4 we find that men, minorities, and the less educated are more likely to lose health insurance. We discuss the minority and education results in more detail in the next section. The important point is that the estimates reported in Specification 4 indicate that the coefficient estimates on the dynamic factors are not sensitive to the inclusion of these controls. We continue to find a strong relationship between health insurance loss and employment changes, employer size changes, and type of employment changes.

\section{IDENTIFYING DYNAMIC FACTORS CORRELATED WITH HEALTH INSURANCE GAIN}

We next examine the factors that are associated with health insurance gain in Table 6 . $^{7}$ Specification 1 of Table 6 reports estimates for our base model. Changes in employment and job characteristics are strongly associated with health insurance gain. As expected, we find that moving from non-employment to employment is associated with an increased probability of gaining health insurance of 4.4 percentage points, relative to individuals who are employed in both years. Note that this is substantially lower than the association between job loss and health insurance loss (12.1 percentage points).

The relationship between finding a job and gaining health insurance appears to be primarily driven by movement into full-time, full-year jobs. Focusing on Specification 3 of Table 6, we find that workers who transit from non-employment to full-time, full-year jobs are the only ones who experience a large, positive and statistically significant increase in the probability of gaining health insurance. These individuals experience an 11.3 percentage point increase relative to workers who have no change in

\footnotetext{
${ }^{7}$ Estimates from probit regressions for the probability of gaining private health insurance demonstrate similar results, except that the coefficients on the welfare and SSI gain variables are smaller.
} 
work commitment. In contrast, the uninsured who do not have jobs in the first survey year and move into part-year employment or part-time, full-year employment are no more likely to gain health insurance. In fact, we find a negative relationship between movement into part-year employment relative to remaining at the same level of work commitment, which is statistically significant in Specifications 3 and 4 . These findings are consistent with the hypothesis that only movement into fulltime, full-year work enables the uninsured who are not employed to gain insurance. Movement into part-year or part-time employment appears to be less beneficial.

Estimates from the CPS generally indicate that individuals who are not employed in both years and individuals who experience job loss are less likely to gain health insurance than individuals who have the same work commitment over the two years. Lengthy spells of non-employment and job loss appear to limit the ability of uninsured individuals to acquire health insurance.

The relationship between employer size and health insurance gain is also strong. Workers who move up in employer size are much more likely to gain health insurance. These workers are 10.9 percentage points more likely to gain health insurance than workers who do not change employer size categories (Specification 1). This positive relationship combined with the strong relationship between employer size loss and health insurance loss are the underlying reasons for why health insurance coverage increases with employer size. Workers moving down in the employer size distribution also have a higher likelihood of gaining health insurance, which is counterintuitive. As noted above, this may partly reflect movement to new employers not captured in our employer change measure.

Looking at the more detailed employer size changes shown in Specification 3, we find evidence that movement from smaller employers to larger employers results in a higher probability of gaining health insurance, and that the increase in probability is larger when the movement in employer size is larger. (The reference category is workers who do not change employer size categories between survey 
years.) As evidence of the latter, we find that movement from a very small employer to a large employer is associated with 5.5 percentage point larger increase in the probability of gaining health insurance than movement from a medium employer to a large employer.

One of the strongest factors associated with health insurance gain is movement from a private employer to a government employer. Workers who move from private to government work are 13.0 to 19.5 percentage points more likely to gain health insurance than are workers remaining in private work. Government employment appears to be a powerful route to becoming insured. The estimates for movement from self-employment to government employment are also positive and large in magnitude in most specifications, but are not statistically significant. Movement from self-employment to private employment is generally not associated with gaining health insurance.

Another important factor is whether the worker experienced an employer change. Employer changes are associated with a 5.5 to 6.7 percentage point higher probability of gaining health insurance. We would expect this if individuals change jobs in order to acquire more comprehensive health insurance, better choices in insurance, or lower costs.

As expected, acquiring welfare or SSI is associated with very high rates of gaining health insurance. Mirroring the findings for health insurance loss, we find that the addition of children to the household is associated with a higher probability of gaining health insurance. We also find that marriage is associated with a higher likelihood of gaining insurance, and spousal job gain is associated with health insurance gain.

\section{Identifying the Causes of Ethnic and Racial Differences in Health Insurance Transitions}

The dynamic factors associated with health insurance transitions have been identified. We now explore the question of how much of the racial differences in health insurance transition rates can be 
explained by group differences in these dynamic factors and other characteristics? It is well known that there exist large racial differences in dynamic employment factors such as job loss and transitions into self-employment. In particular, blacks and Latinos have higher rates of job loss than whites and blacks and have lower rates of becoming self-employed than whites (see Fairlie 2006). Can these dynamic factors explain why minorities have higher rates of health insurance transitions or do they work to lessen differences in health insurance transition rates? Another important question is how much each of the dynamic factors explains of the racial gaps in health insurance transition rates.

To explore these issues further, we employ a variant of the familiar technique of decomposing inter-group differences in a dependent variable into those due to different observable characteristics across groups and those due to different "prices" of characteristics of groups (see Blinder 1973 and Oaxaca 1973). The technique that we describe here takes into account the nonlinearity of the probit regressions discussed above (see Fairlie 1999, 2005 for more details). ${ }^{8}$

For a linear regression, the standard Blinder-Oaxaca decomposition of the white/minority gap in the average value of the dependent variable, $\mathrm{Y}$, can be expressed as:

(6.1) $\bar{Y}^{W}-\bar{Y}^{M}=\left\lfloor\left(\bar{X}^{W}-\bar{X}^{M}\right) \hat{\beta}^{W}\right\rfloor+\left\lfloor\bar{X}^{M}\left(\hat{\beta}^{W}-\hat{\beta}^{M}\right)\right\rfloor$,

where $\bar{X}^{j}$ is a row vector of average values of the independent variables and $\hat{\beta}^{j}$ is a vector of coefficient estimates for race $j$. For a nonlinear equation, such as $Y=F(X \hat{\beta})$, the decomposition can be written as:

$$
\bar{Y}^{W}-\bar{Y}^{M}=\left[\sum_{i=1}^{N^{W}} \frac{F\left(X_{i}^{W} \hat{\beta}^{W}\right)}{N^{W}}-\sum_{i=1}^{N^{M}} \frac{F\left(X_{i}^{M} \hat{\beta}^{W}\right)}{N^{M}}\right]+\left[\sum_{i=1}^{N^{M}} \frac{F\left(X_{i}^{M} \hat{\beta}^{W}\right)}{N^{M}}-\sum_{i=1}^{N^{M}} \frac{F\left(X_{i}^{M} \hat{\beta}^{M}\right)}{N^{M}}\right]
$$

\footnotetext{
${ }^{8}$ SAS programs are available for the non-linear decomposition technique at http://people.ucsc.edu/ rfairlie/decomposition, and a Stata program and help file is available by entering "ssc install fairlie" in Stata.
} 
where $N^{j}$ is the sample size for race $j$. This alternative expression for the decomposition is used because $\bar{Y}$ does not necessarily equal $F(\bar{X} \hat{\beta})$. In both (6.1) and (6.2), the first term in brackets represents the part of the racial gap that is due to group differences in distributions of $X$, and the second term represents the part due to differences in the group processes determining levels of $Y$. The second part of the decomposition may capture racial differences in preferences for health insurance coverage, discrimination in the provision of health insurance, other unmeasurable differences, and racial differences in the effects of trigger events on health insurance transitions. We do not focus on these factors because of the difficulty in identifying their separate effects and instead focus on first or explained part of the decomposition. To calculate the decomposition, we define $\bar{Y}$ as the health insurance transition rate (loss or gain) or exit rate and $F$ as the logistic cumulative distribution function.

An equally valid method of calculating the decomposition is to use the minority coefficient estimates, $\hat{\beta}^{M}$, as weights in estimating the contributions from group differences in the independent variables. This alternative method of calculating the decomposition often provides different estimates, which is the familiar index problem with the Blinder-Oaxaca decomposition technique. A third commonly-used alternative is to weight the first term of the decomposition expression using coefficient estimates from a pooled sample of the two groups or all groups (see Oaxaca and Ransom 1994 for example). We follow this approach to calculate the decompositions. In particular, we use coefficient estimates from regressions that include pooled samples of all ethnic and racial groups.

The first term in (6.2) provides an estimate of the contribution of racial differences in the entire set of independent variables to the racial gap, but we are particularly interested in identifying the effects of group differences in specific variables, such as job loss and employer size changes. To identify contributions from these variables an additional calculation is needed. To simplify, assume that $X$ 
includes two variables, $X_{1}$ and $X_{2}$. Using coefficient estimates from a logit regression for a pooled sample, $\hat{\beta}^{*}$, the independent contribution of $X_{1}$ to the racial gap can then be expressed as:

(6.3) $\frac{1}{N^{M}} \sum_{i=1}^{N^{M}} F\left(\hat{\alpha}^{*}+X_{1 i}^{W} \hat{\beta}_{1}^{*}+X_{2 i}^{W} \hat{\beta}_{2}^{*}\right)-F\left(\hat{\alpha}^{*}+X_{1 i}^{M} \hat{\beta}_{1}^{*}+X_{2 i}^{W} \hat{\beta}_{2}^{*}\right)$

Similarly, the contribution of $X_{2}$ can be expressed as:

(6.4) $\frac{1}{N^{M}} \sum_{i=1}^{N^{M}} F\left(\hat{\alpha}^{*}+X_{1 i}^{M} \hat{\beta}_{1}^{*}+X_{2 i}^{W} \hat{\beta}_{2}^{*}\right)-F\left(\hat{\alpha}^{*}+X_{1 i}^{M} \hat{\beta}_{1}^{*}+X_{2 i}^{M} \hat{\beta}_{2}^{*}\right)$.

The contribution of each variable to the gap is thus equal to the change in the average predicted probability from replacing the black distribution with the white distribution of that variable while holding the distributions of the other variable constant. ${ }^{9}$ A useful property of this technique is that the sum of the contributions from individual variables will be equal to the total contribution from all of the variables evaluated with the full sample.

Table 7 reports estimates from this procedure for decomposing the gaps between whites and each minority group in health insurance loss rates. The specification used to calculate the decompositions includes the basic trigger events reported in Specification 1 of Table 6, the race dummies, education, and demographic controls (see Appendix 2). The individual contributions from racial differences in job loss, employer size changes, employer type changes, employer changes, welfare or SSI loss, change in family characteristics, education level and demographic characteristics are reported. We first describe the results for blacks. Blacks are much more likely than whites to lose health insurance annually, with a gap of 0.0563 . Higher rates of job loss contribute substantially to the gap in health insurance loss rates.

\footnotetext{
${ }^{9}$ The calculation of (6.3) and (6.4), however, is not possible without first matching the white distribution of $\mathrm{X}_{1}$ and the minority distribution of $\mathrm{X}_{2}$. We draw a random subsample of whites with a sample size equal to $\mathrm{N}_{\mathrm{M}}$ and match it to the minority sample based on the predicted probability of the dependent variable. To approximate the use of the entire white sample, we draw 1000 random white samples for matching and calculate the mean value of estimates from all of these matched samples. See Fairlie (2005) for more details.
} 
Among insured blacks, 4.5 percent lose their jobs annually (see Appendix 1 for means). For whites, the percent is lower at 3.0 percent. These disparities in job loss contribute to the higher rate of health insurance loss among blacks. A higher rate of being jobless in both years among blacks also contributes to the higher likelihood of health insurance loss. These factors explain 30.2 percent of the gap in health insurance loss rates and are the largest measurable contributing factor.

Although employer size changes, employer type changes and employer changes are important factors correlated with losing health insurance, they do not contribute to why blacks are more likely to lose health insurance than whites. Black/white differences in these factors are not large enough to generate sizeable contributions.

Insured blacks are more likely to lose welfare or SSI from one year to the next. Because both of these dynamic factors are strongly associated with health insurance loss they contribute to the higher likelihood of losing health insurance among blacks. Welfare and SSI loss explain 7.7 percent of the black/white gap in health insurance loss rates.

Similar to changes in job characteristics, changes in family characteristics do not contribute substantially to higher rates of insurance loss among blacks. Insured blacks and whites do not differ much in the annual likelihood of divorce, having children leave the household, or having a spousal job loss.

Although not the focus of this analysis, we also estimate the contribution from racial differences in education levels. Education is measured at the first survey date. The individual's education level is a strong predictor of who loses health insurance. Less educated workers are more likely to be employed in less-skilled jobs that suffer more from insurance loss. Racial differences in education explain 15.1 percent of the black/white gap in health insurance loss rates. Racial differences in additional demographic characteristics (sex, marital status, number of children, age, disability, veteran status, 
regions and central city status) also contribute to the gaps in health insurance loss rates. All of these characteristics are measured at the first survey date.

Estimates for the contributions to the white/Latino gap in health insurance loss rates are reported in the second column of Table 7. The two most important contributing factors for Latinos are job loss and education. Higher rates of job loss and remaining jobless for two consecutive years contribute substantially to the higher rate of insurance loss among Latinos. The contribution for job loss is roughly similar to that for blacks (-0.0164), but the total gap is much larger resulting in a smaller percent contribution (16.0 percent). The gap in health insurance loss rates is 10.2 percentage points. Lower levels of education among Latinos also contribute substantially to the higher rate of insurance loss. Education differences explain 17.2 percent of the gap in health insurance loss rates.

The gap between whites and Asian in health insurance loss rates is partly explained by differences in job loss. Among insured Asians, 3.9 percent experience a loss of their health insurance compared to 3.0 percent of insured whites. These differences explain 31.1 percent of the gap in health insurance loss rates. Interestingly, Asian/white differences in education provide a negative contribution to the gap in health insurance loss rates. Asians have higher education levels than whites, on average, which works to decrease their rates of health insurance loss relative to whites. All else equal, Asians should have a lower health insurance loss rate than whites given their higher education levels. In fact, if Asians were not more educated than whites then the disparity between Asians and whites in health insurance loss rates would be even larger than it currently is.

\section{RACIAL DIFFERENCES IN GAINING HEALTH INSURANCE}


Table 8 reports estimates for decompositions of white/minority gaps in rates of gaining health insurance. ${ }^{10}$ For both blacks and Asians, the rate of gaining health insurance is similar to the white rate. Decomposition estimates are reported, but the percent contributions are suppressed because they can be misleading when the gaps are so small. In contrast, uninsured Latinos are much less likely than uninsured whites to gain health insurance annually. The only major contributing factor to this gap is the difference in education levels. The lower education levels of Latinos are resulting in a lower chance that they will become insured in the following year (see Appendix 3 for means). This may be because lesseducated Latinos are more likely to be working in less-skilled jobs that do not offer health insurance.

\section{Conclusions}

Racial differences in health insurance coverage are a source of concern because they have implications for the quality of care received, costs of health care, and ultimately health outcomes (Kaiser Commission on Medicaid and the Uninsured 2003). The focus on health insurance coverage at a point in time and its consequences, however, may greatly understate the problem of racial disparities in uninsurance in the United States. Estimates from the matched CPS data indicate that health insurance coverage over time is volatile, especially for minorities. Given these concerns and the extensive literature focused on racial inequality in other areas, the literature on the causes of racial differences in the dynamics of health insurance coverage is relatively underdeveloped. In this paper, we explore the dynamics of health insurance for minority workers using matched CPS data in an attempt to better understand the disparities in health insurance coverage that appear in cross-sectional data.

Estimates from a simple decomposition of racial differences in static health insurance coverage rates into group differences in transition rates into and out of health insurance coverage reveal several

\footnotetext{
${ }^{10}$ Estimates from the specification used in the decomposition are reported in Appendix 2.
} 
interesting patterns. First, the low rate of health insurance coverage among African-Americans is due almost entirely due to much higher annual rates of losing health insurance than whites. Among the uninsured, African-Americans have similar rates of gaining health insurance in the following year as whites. In contrast to these findings, differences in health insurance coverage between Latinos and whites are due to group differences in both the rate of health insurance loss and gain. The higher rate of health insurance loss among Latinos relative to whites is responsible for 63 to 80 percent of the large gap in health insurance coverage rates. Finally, estimates for Asians, which have not been studied extensively in the literature, indicate that almost the entire Asian/white gap in health insurance coverage rates is accounted for by the relatively high rate of losing health insurance among Asians. Asians are less likely to be insured and have much higher rates of insurance loss than whites.

Results from a non-linear decomposition analysis based on regression estimates of the dynamic factors associated with health insurance loss indicate that two main factors are responsible for differences in health insurance loss between working-age whites and minorities: job loss and education level. Higher rates of job loss account for 30 percent of the health insurance gap for African-Americans and Asians, and 16 percent of the health insurance gap for Latinos. Lower levels of education explain roughly 15 percent of the gap for African-Americans and Latinos (Asians' higher levels of education serve to close the gap). Higher rates of welfare and SSI participation among African-Americans also contribute to the gap in health insurance loss by 8 percent.

The results for the health insurance gain decomposition are less compelling, in part because the gaps in health insurance gain are smaller than for loss, and pertain largely to one minority groupLatinos. For Latinos, the main contributor to the lower rates of health insurance gain relative to whites is their lower average level of education. There is not a parallel finding to the loss results with regard to job gain; where as higher levels of job loss added to the health insurance loss gap for Latinos, lower 
levels of job gain do not contribute to the health insurance gain gap for this group. The findings for Latinos are important because the gaps in insurance coverage between Latinos and non-Latino whites have been widening over the past two decades (Rutledge and McLaughlin 2006).

These findings are very much in line with the literature on minority employment patterns, which indicates higher rates of job loss for minorities than whites. Tabulations from our data indicate that over a two-year period, African-Americans are one and a half times as likely as whites to lose a job, Latinos are 1.4 times as likely to lose a job as whites, and Asians are 1.3 times as likely. Even if these workers become re-employed immediately, their job loss is still associated with higher rates of uninsurance. Socalled "job movers" are at a higher risk of being unisured because they are less likely to work for employers who offer health insurance coverage to any workers, and are also less eligible for coverage even if their employer covers others (Farber and Levy 2000).

Recent mandated insurance proposals in states such as California, Massachusetts, and Oregon place particular focus on insuring part-time or seasonal workers, those working multiple jobs, and those working for smaller (but not very small) employers. To the extent that job loss is associated with new job acquisition, these proposals would help to reduce the disparity in health insurance loss rates for whites and minorities. However, these proposals do not specifically address the problem of uninsurance among the unemployed. Given these disparities in job loss, solutions to the problem of uninsurance or intermittent insurance might look to insurance smoothing across periods of unemployment or job transition. Indeed, those who are recently unemployed have access to COBRA, in which they have access to paid insurance to cover themselves while unemployed for a period of time. However, COBRA insurance is expensive and according to Madrian (1998), only 20 percent of unemployed workers qualifying for COBRA elected to use the program. 
Our findings indicate that policymakers concerned with racial and ethnic disparities in health insurance coverage should be concerned about the link between job loss and health insurance loss, both of which are more prevalent among minority families. This double disadvantage is likely to trigger other negative outcomes, including health-related and other factors. 


\section{References}

Baker, David W., Joseph J. Sudano, Jeffrey M. Albert, Elaine A. Borawski, and Avi Dor. 2001. "Lack of Health Insurance and Decline in Overall Health in late Middle Age.” The New England Journal of Medicine 345(15) 1106-1112.

Bennefield, Robert L. 1996. "A Comparative Analysis of Health Insurance Coverage Estimates: Data from CPS and SIPP," Paper presented at the Joint Statistical Meetings, American Statistical Association.

Bhandari, Shailesh. 2004. "People with Health Insurance: A Comparison of Estimates from Two Surveys," The Survey of Income and Program Participation, U.S. Census Bureau Working Paper No. 243.

Bhandari, Shailesh and Robert Mills. 2003. Dynamics of Economic Well-Being: Health Insurance 1996-1999. U.S. Bureau of the Census Current Population Reports P70-92. Washington, D.C.: Government Printing Office.

Blinder, Alan S. 1973. "Wage Discrimination: Reduced Form and Structural Variables." Journal of Human Resources, 8, pp. 436-455.

Chernew, Michael E., and Richard A. Hirth. 2001. "Modeling the Causes and Consequences of Lack of Health Insurance Coverage: Gaps in the Literature,” Economic Research Initiative on the Uninsured Working Paper, University of Michigan.

Congressional Budget Office. 2003. How Many People Lack Health Insurance and For How Long? Washington, DC: Congressional Budget Office.

Czajka, John L. and Cara Olsen. 2000. The Effects of Trigger Events on Changes in Children's Health Insurance Coverage. Princeton, NJ: Mathematica Policy Research, Inc.

DeNasvas-Walt, Carmen, Bernadette D. Proctor, and Robert J. Mills. 2004. Income, Poverty, and Health Insurance Coverage in the United States: 2003. U.S. Bureau of the Census Current Population Reports P60-226. Washington, D.C.: Government Printing Office.

Fairlie, Robert W. 1999. "The Absence of the African-American Owned Business: An Analysis of the Dynamics of Self-Employment." Journal of Labor Economics, 17(1): 80-108.

2005. "An Extension of the Blinder-Oaxaca Decomposition Technique to Logit and Probit Models," Journal of Economic and Social Measurement, 30(4): 305-316.

. 2006. "Entrepreneurship among Disadvantaged Groups: An Analysis of the Dynamics of SelfEmployment by Gender, Race and Education," The Life Cycle of Entrepreneurial Ventures, International Handbook Series on Entrepreneurship, Vol. 3, ed. Simon Parker. Springer: New York. 
Fairlie, Robert W. and Rebecca A. London. 2005. "The Dynamics of Health Insurance Coverage: Factors Correlated with Insurance Gain and Loss among Adults.” Report submitted to the U.S. Department of Labor.

Farber, Henry S., and Helen Levy. 2000. "Recent Trends in Employer-Sponsored Health Insurance Coverage: Are Bad Jobs Getting Worse?" Journal of Health Economics. 19(1): 93-119.

Gilleskie, Donna and Byron Lutz. 2002. "The Impact of Employer-Provided Health Insurance on Dynamic Employment Transitions.” Journal of Human Resources 37(1): 129-155.

Institute of Medicine of the National Academies. 2003. Hidden Costs, Value Lost : Uninsurance in America. Washington, DC: National Academies Press.

Kaiser Commission on Medicaid and the Uninsured. 2003. Access to Care for the Uninsured: An Update. Washington, DC: Henry J. Kaiser Family Foundation.

Kapur, Kanika. 1998. “The Impact of Health on Job Mobility: A Measure of Job Lock.” Industrial and Labor Relations Review 51(2): 282-298.

Levy, Helen. 2002. “The Economic Consequences of Being Uninsured.” Economic Research Initiative on the Uninsured (ERIU) Working Paper 12.

Levy, Helen and David Meltzer. 2001. "What Do We Really Know About Whether Health Insurance Affects Health?” Unpublished manuscript, University of Chicago.

Madrian, Brigitte C. 1994. "Employment-Based Health Insurance and Job Mobility: Is There Evidence of Job-Lock?” The Quarterly Journal of Economics. 109(1): 27-54.

. 1998. “Health Insurance Portability: Consequences of COBRA.” Regulation: The Cato Review of Business and Government 21(1): 27-31.

Madrian, Brigette C., and Lars John Lefgren. 2000. "An Approach to Longitudinally Matching Current Population Survey (CPS) Respondents," Journal of Economic and Social Measurement, 26: 3162.

Marquis, Susan and Kanika Kapur. 2003. "Employment Transitions And Continuity of Health Insurance: Implications For Premium Assistance Programs.” Health Affairs 22(5): 198-209.

McBride, Timothy D. 1997. “Uninsured Spells of the Poor: Prevalence and Duraction.” Health Care Financing Review 19(1): 145-161.

McWilliams, J. Michael, Alan M. Zaslavsy, Ellen Meara and John Z. Ayanian. 2003. "Impact of Medicare Coverage on Basic Clinical Services for Previously Uninsured Adults.” Journal of the American Medical Association 290(6): 757-764. 
Monheit, Alan C., Jessica P. Vistnes, and Samuel H. Zuvekas. 2001. Stability and change in health insurance: new estimates from the 1996 MEPS. MEPS Research Findings No.18. AHRQ Pub. No. 02-0006. Rockville, MD: Agency for Healthcare Research and Quality.

Oaxaca, Ronald. 1973. "Male-Female Wage Differentials in Urban Labor Markets," International Economic Review, 14 (October), 693-709.

Oaxaca, Ronald, and Michael Ransom. 1994. "On Discrimination and the Decomposition of Wage Differentials," Journal of Econometrics, 61, 5-21.

Rutledge, Matt, and Catherine McLaughlin. 2006. "Coverage Transitions in Hispanic vs. White NonHispanic Populations: Trends in the Last 20 Years," University of Michigan, Economic Research Initiative on the Uninsured Working Paper.

Schoen, Cathy and Catherine DesRoches. 2000. "Uninsured and Unstably Insured: The Importance of Continuous Insurance Coverage.” Health Services Research 35(1): 187-206.

Short, Pamela Farley and Deborah R. Gaefe. 2003. “Battery-Powered Health Insurance? Stability in Coverage of the Uninsured.” Health Affairs 22(6): 244-255.

Sudano, Joseph J. and David W. Baker. "Intermittent Lack of Health Insurance Coverage and Use of Preventive Services.” American Journal of Public Health 93(1): 130-138.

Swartz, Katherine. 1986. "Interpreting the Estimates from Four National Surveys of the Number of People without Health Insurance," Journal of Economic and Social Measurement, 14: 233-242.

Swartz, Katherine, John Marcotte and Timothy D. McBride. 1993. "Personal Characteristics and Spells without Health Insurance.” Inquiry 30(Spring): 64-76.

Swartz, Katherine and Timothy D. McBride. 1990. "Spells without Health Insurance: Distributions of Durations and Their Link to Point-in-Time Estimates of the Uninsured.” Inquiry 27(Fall): 281288.

U.S. Census Bureau. 1995. “Health Insurance Coverage - 1994.” Report No. P60-190, October 1995, http://www.census.gov/prod/1/pop/p60-190.pdf

U.S. Census Bureau. 2004. "Income, Poverty, and Health Insurance Coverage in the United States: 2003.” Report No. P60-226, August 2004, http:/www.census.gov/prod/2004pubs/p60-226.pdf.

Zuckerman, Stephen and Jennifer Haley. 2004. "Variation and Trends in the Duration of Uninsurance," Urban Institute Discussion Paper 04-10. Washington, DC: The Urban Institute. 
Figure 1

Health Insurance Loss Rates by Race/Ethnicity

Current Population Survey, Matched Annual Demographic Surveys (1996-2004)

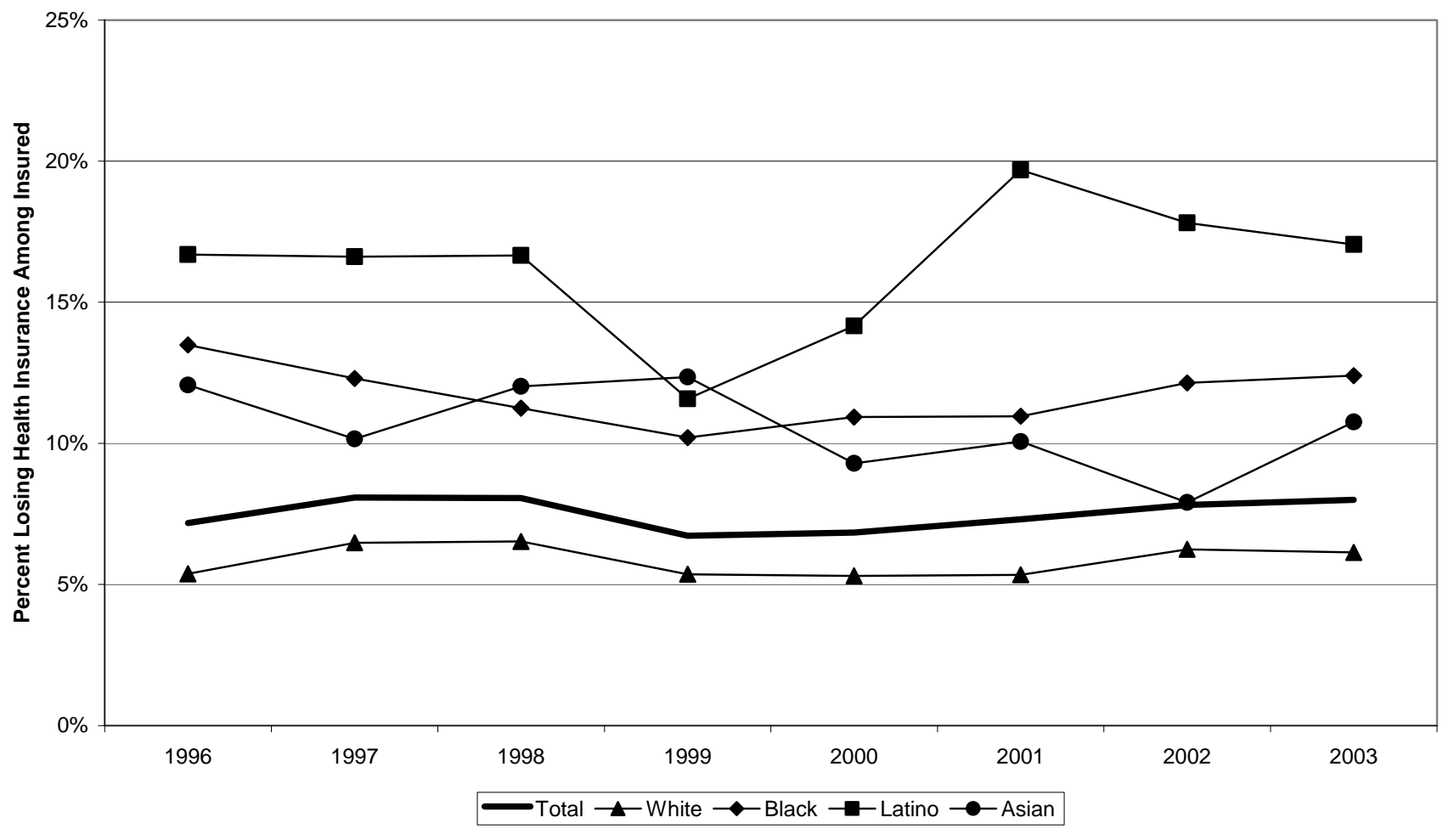


Figure 2

Health Insurance Gain Rates by Race/Ethnicity

Current Population Survey, Matched Annual Demographic Surveys (1996-2004)

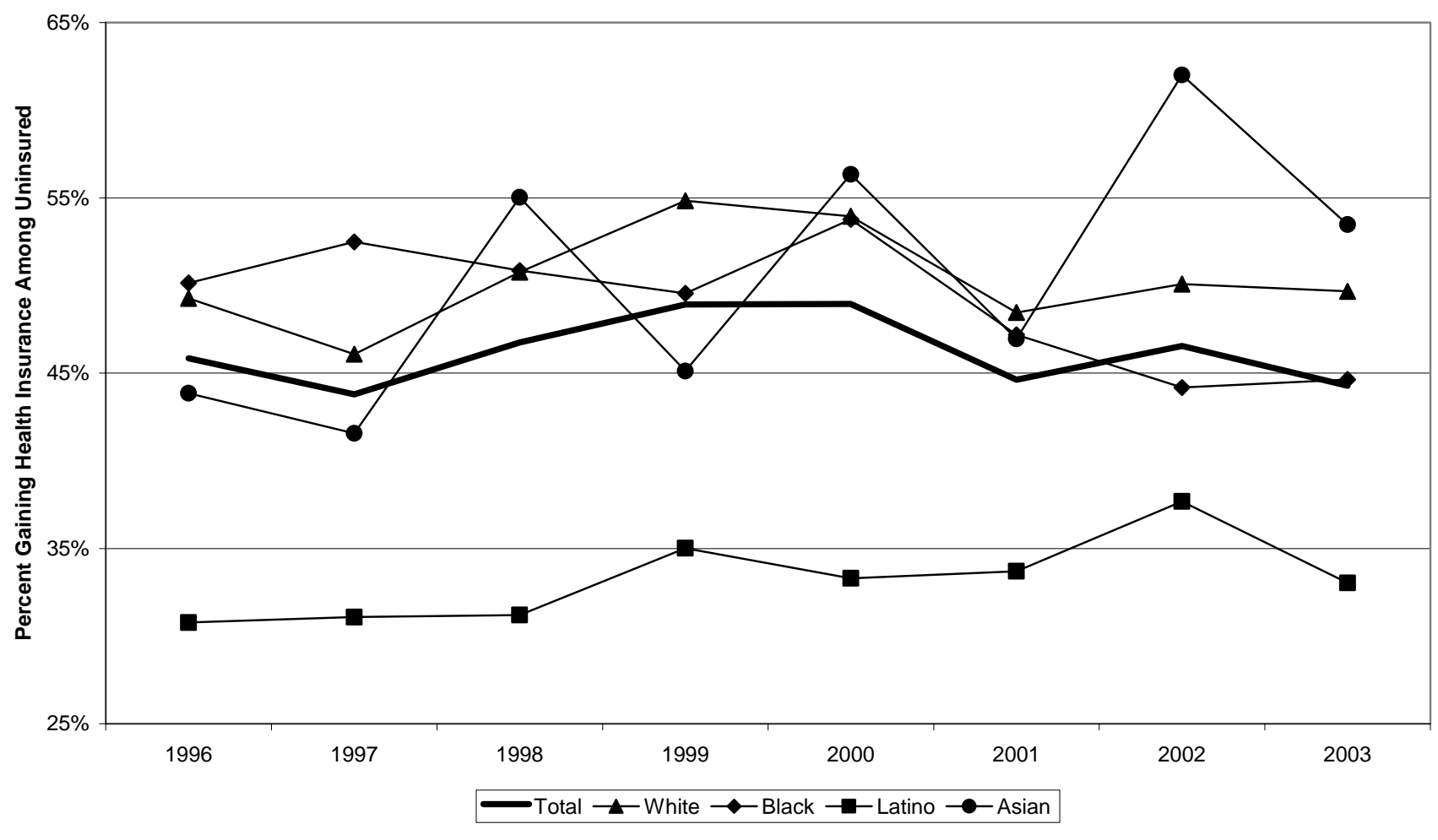


Table 1

Health Insurance Transition Rates for Selected Demographic Groups

Current Population Survey, Matched Annual Demographic Surveys (1996-2004)

\begin{tabular}{lrrrrrr} 
& \multicolumn{2}{c}{$\begin{array}{c}\text { Health Insurance } \\
\text { Coverage }\end{array}$} & \multicolumn{2}{c}{$\begin{array}{c}\text { Health Insurance Gain } \\
\text { (Among Uninsured) }\end{array}$} & $\begin{array}{c}\text { Health Insurance Loss } \\
\text { (Among Insured) }\end{array}$ \\
& Percent & $\mathrm{N}$ & Percent & $\mathrm{N}$ & Percent & $\mathrm{N}$ \\
\hline Total & $85.6 \%$ & 166,123 & $46.2 \%$ & 23,093 & $7.5 \%$ & 143,030 \\
White & $89.2 \%$ & 129,230 & $50.4 \%$ & 14,171 & $5.8 \%$ & 115,059 \\
Black & $80.5 \%$ & 14,826 & $49.2 \%$ & 2,824 & $11.7 \%$ & 12,002 \\
Latino & $66.9 \%$ & 13,552 & $33.3 \%$ & 4,450 & $16.3 \%$ & 9,102 \\
Asian & $81.5 \%$ & 6,178 & $50.0 \%$ & 1,055 & $10.5 \%$ & 5,123 \\
\hline
\end{tabular}

Notes: (1) The sample consists of individuals (ages 25-55) in the first year surveyed. (2) Health insurance is measured in the first survey year, and health insurance transtions are measured from the first to second survey years. (3) All estimates are calculated using sample weights provided by the CPS. 
Table 2

Health Insurance Coverage Rate Simulations by Race

$\underline{\text { Rate of health insurance gain }}$

Rate of health insurance loss

Difference

\begin{tabular}{|c|c|c|c|c|c|c|}
\hline & & Black = & $11.7 \%$ & White $=$ & $5.8 \%$ & \\
\hline Black = & $49.2 \%$ & \multicolumn{2}{|c|}{$80.8 \%$} & \multicolumn{2}{|c|}{$89.4 \%$} & $8.6 \%$ \\
\hline White $=$ & $50.4 \%$ & \multicolumn{2}{|c|}{$81.2 \%$} & \multicolumn{2}{|c|}{$89.6 \%$} & $8.4 \%$ \\
\hline \multirow[t]{2}{*}{ Difference } & & \multicolumn{2}{|c|}{$0.4 \%$} & \multicolumn{2}{|c|}{$0.2 \%$} & $8.8 \%$ \\
\hline & & Latino $=$ & $16.3 \%$ & White $=$ & $5.8 \%$ & \\
\hline Latino $=$ & $33.3 \%$ & \multicolumn{2}{|c|}{$67.1 \%$} & \multicolumn{2}{|c|}{$85.1 \%$} & $17.9 \%$ \\
\hline White = & $50.4 \%$ & \multicolumn{2}{|c|}{$75.6 \%$} & \multicolumn{2}{|c|}{$89.6 \%$} & $14.1 \%$ \\
\hline Difference & & \multicolumn{2}{|c|}{$8.4 \%$} & \multicolumn{2}{|c|}{$4.5 \%$} & $22.5 \%$ \\
\hline & & Asian $=$ & $10.5 \%$ & White $=$ & $5.8 \%$ & \\
\hline Asian= & $50.0 \%$ & \multicolumn{2}{|c|}{$82.6 \%$} & \multicolumn{2}{|c|}{$89.5 \%$} & $6.9 \%$ \\
\hline White = & $50.4 \%$ & \multicolumn{2}{|c|}{$82.7 \%$} & \multicolumn{2}{|c|}{$89.6 \%$} & $6.9 \%$ \\
\hline Difference & & \multicolumn{2}{|c|}{$0.1 \%$} & \multicolumn{2}{|c|}{$0.1 \%$} & $7.0 \%$ \\
\hline
\end{tabular}

Notes: (1) The sample consists of adults ages 25-55. (2) All estimates are calculated using sample weights provided by the CPS. 
Table 3

Health Insurance Transitions by Changes in Job Status Current Population Survey, Matched Annual Demographic Surveys (1996-2004)

\begin{tabular}{lcc} 
& \multicolumn{2}{c}{ Health Insurance Loss } \\
\cline { 2 - 3 } No Job in $\mathrm{t}$ & $9.3 \%$ & Job in $\mathrm{t}+1$ \\
\cline { 2 - 3 } Job in $\mathrm{t}$ & $19.9 \%$ & $16.0 \%$ \\
& & $6.6 \%$ \\
\hline & & Health Insurance Gain \\
\cline { 2 - 3 } & & Job in $\mathrm{t}+1$ \\
\cline { 2 - 3 } No Job in $\mathrm{t}$ & $41.0 \%$ & $45.0 \%$ \\
Job in $\mathrm{t}$ & $42.3 \%$ & $47.7 \%$ \\
\hline
\end{tabular}

Notes: (1) The sample consists of individuals (ages 25-55) in the first year surveyed. (2) Health insurance coverage is defined as coverage at any time during the calendar year prior to the survey date (survey year). Health insurance coverage transtions are measured from the first to second survey years. (3) All estimates are calculated using sample weights provided by the CPS. 
Table 4

Health InsuranceTransitions by Changes in Employer Size

Current Population Survey, Matched Annual Demographic Surveys (1996-2004)

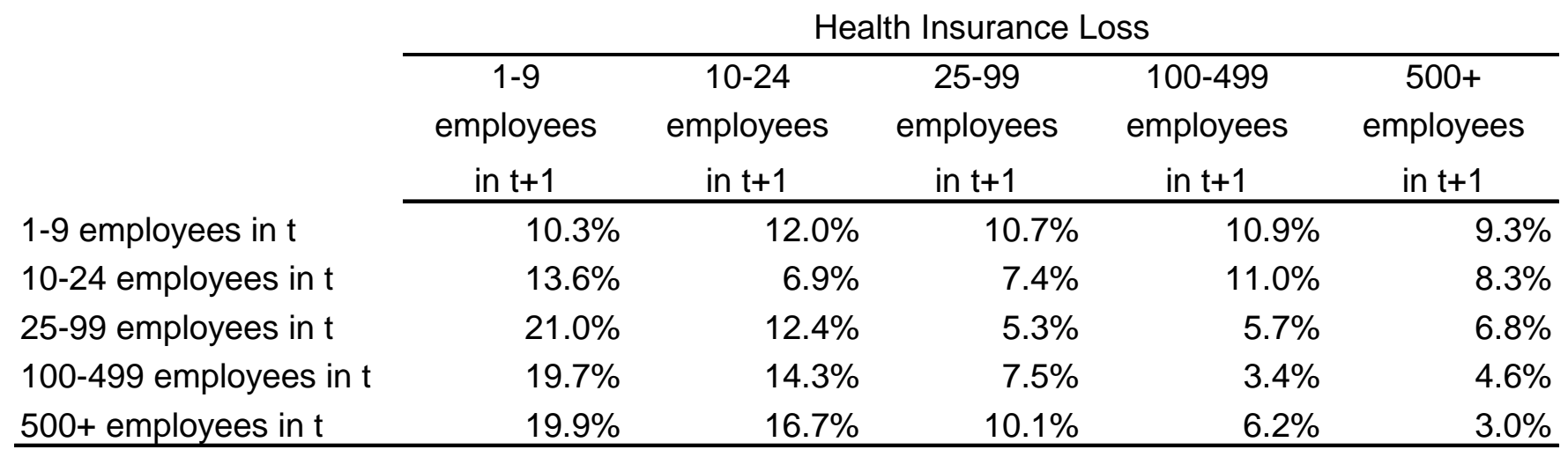

\begin{tabular}{|c|c|c|c|c|c|}
\hline & \multicolumn{5}{|c|}{ Health Insurance Gain } \\
\hline & $\begin{array}{c}1-9 \\
\text { employees } \\
\text { in } t+1\end{array}$ & $\begin{array}{c}10-24 \\
\text { employees } \\
\text { in } t+1\end{array}$ & $\begin{array}{c}25-99 \\
\text { employees } \\
\text { in } t+1\end{array}$ & $\begin{array}{c}100-499 \\
\text { employees } \\
\text { in } t+1\end{array}$ & $\begin{array}{c}500+ \\
\text { employees } \\
\text { in } t+1\end{array}$ \\
\hline 1-9 employees in $t$ & $31.6 \%$ & $38.9 \%$ & $52.6 \%$ & $58.9 \%$ & $67.7 \%$ \\
\hline 10-24 employees in t & $38.3 \%$ & $36.9 \%$ & $43.8 \%$ & $60.3 \%$ & $61.5 \%$ \\
\hline 25-99 employees in t & $34.2 \%$ & $44.6 \%$ & $43.8 \%$ & $52.9 \%$ & $62.8 \%$ \\
\hline 100-499 employees in t & $42.2 \%$ & $49.6 \%$ & $52.2 \%$ & $57.2 \%$ & $63.8 \%$ \\
\hline $500+$ employees in t & $40.9 \%$ & $45.1 \%$ & $59.7 \%$ & $63.4 \%$ & $63.0 \%$ \\
\hline
\end{tabular}

Notes: (1) The sample consists of individuals (ages 25-55) in the first year surveyed. (2) Health insurance coverage is defined as coverage at any time during the calendar year prior to the survey date (survey year). Health insurance coverage transtions are measured from the first to second survey years. (3) All estimates are calculated using sample weights provided by the CPS. 
Table 5

Probit Regressions for Probability of Health Insurance Loss - Marginal Effects Current Population Survey, Matched Annual Demographic Surveys (1996-2004)

\begin{tabular}{|c|c|c|c|c|c|c|c|c|}
\hline \multirow[b]{2}{*}{ Correlated Factor } & \multicolumn{8}{|c|}{ Specification } \\
\hline & $(1)$ & & $(2)$ & & (3) & & $(4)$ & \\
\hline \multirow[t]{2}{*}{ No job in both years } & 0.0527 & ** & 0.0597 & ** & 0.0594 & ** & 0.0513 & $\star \star$ \\
\hline & $(0.0024)$ & & $(0.0024)$ & & $(0.0024)$ & & $(0.0026)$ & \\
\hline \multirow[t]{2}{*}{ Job loss } & 0.1212 & $\star \star$ & & & & & & \\
\hline & $(0.0031)$ & & & & & & & \\
\hline \multirow[t]{2}{*}{ No job to job } & 0.0956 & ** & 0.1023 & ** & 0.1017 & ** & 0.0896 & ** \\
\hline & $(0.0037)$ & & $(0.0037)$ & & $(0.0037)$ & & $(0.0036)$ & \\
\hline \multirow[t]{2}{*}{ Employer size loss } & 0.0429 & ** & 0.0419 & ** & & & & \\
\hline & (0.0019) & & $(0.0019)$ & & & & & \\
\hline \multirow[t]{2}{*}{ Employer size gain } & 0.0098 & ** & 0.0088 & ** & & & & \\
\hline & $(0.0021)$ & & $(0.0021)$ & & & & & \\
\hline \multirow{2}{*}{$\begin{array}{l}\text { Private employer to self- } \\
\text { employment }\end{array}$} & 0.0424 & $\star \star$ & 0.0410 & $\star \star$ & 0.0187 & ** & 0.0310 & ** \\
\hline & $(0.0039)$ & & $(0.0039)$ & & $(0.0042)$ & & $(0.0039)$ & \\
\hline \multirow{2}{*}{$\begin{array}{l}\text { Government employer to private } \\
\text { employer }\end{array}$} & 0.0067 & & 0.0051 & & 0.0094 & * & 0.0128 & ** \\
\hline & $(0.0041)$ & & $(0.0041)$ & & $(0.0041)$ & & $(0.0039)$ & \\
\hline \multirow{2}{*}{$\begin{array}{l}\text { Government employer to self- } \\
\text { employment }\end{array}$} & 0.0528 & ** & 0.0466 & ** & 0.0146 & & 0.0308 & ** \\
\hline & $(0.0116)$ & & $(0.0116)$ & & $(0.0118)$ & & $(0.0110)$ & \\
\hline \multirow[t]{2}{*}{ Other employer type change } & 0.0083 & * & 0.0066 & * & 0.0039 & & 0.0143 & ** \\
\hline & $(0.0033)$ & & $(0.0033)$ & & $(0.0033)$ & & $(0.0031)$ & \\
\hline \multirow[t]{2}{*}{ Employer change } & 0.0361 & $\star *$ & 0.0329 & ** & 0.0302 & ** & 0.0255 & ** \\
\hline & $(0.0018)$ & & $(0.0018)$ & & $(0.0018)$ & & $(0.0017)$ & \\
\hline \multirow[t]{2}{*}{ Welfare loss } & 0.0964 & ** & 0.0938 & ** & 0.0933 & ** & 0.0561 & ** \\
\hline & $(0.0052)$ & & $(0.0052)$ & & $(0.0052)$ & & $(0.0049)$ & \\
\hline \multirow[t]{2}{*}{ SSI loss } & 0.0643 & ** & 0.0638 & ** & 0.0632 & ** & 0.0439 & ** \\
\hline & $(0.0058)$ & & $(0.0057)$ & & $(0.0057)$ & & $(0.0054)$ & \\
\hline \multirow[t]{2}{*}{ Children to no children } & -0.0089 & * & -0.0090 & * & -0.0086 & * & 0.0016 & \\
\hline & $(0.0044)$ & & $(0.0044)$ & & $(0.0044)$ & & $(0.0042)$ & \\
\hline \multirow[t]{2}{*}{ Married to not married } & 0.0478 & $\star *$ & 0.0467 & ** & 0.0457 & ** & 0.0534 & ** \\
\hline & $(0.0058)$ & & $(0.0058)$ & & $(0.0058)$ & & $(0.0054)$ & \\
\hline \multirow[t]{2}{*}{ Spousal job loss } & 0.0470 & ** & 0.0474 & ** & 0.0464 & ** & 0.0538 & ** \\
\hline & $(0.0037)$ & & $(0.0037)$ & & $(0.0037)$ & & $(0.0035)$ & \\
\hline
\end{tabular}

(continued) 
Table 5 (Continued)

\begin{tabular}{|c|c|c|c|c|c|c|c|}
\hline \multirow[b]{2}{*}{ Correlated Factor } & \multicolumn{7}{|c|}{ Specification } \\
\hline & $(1)$ & $(2)$ & & $(3)$ & & $(4)$ & \\
\hline \multirow[t]{2}{*}{ Full-time, full-year to no job } & & 0.1644 & ** & 0.1633 & ** & 0.1396 & ** \\
\hline & & $(0.0049)$ & & $(0.0049)$ & & $(0.0046)$ & \\
\hline \multirow[t]{2}{*}{ Full-time, full-year to part year } & & 0.0506 & $\star \star$ & 0.0495 & ** & 0.0424 & ** \\
\hline & & $(0.0026)$ & & $(0.0026)$ & & $(0.0025)$ & \\
\hline \multirow{2}{*}{$\begin{array}{l}\text { Full-time, full-year to part-time, } \\
\text { full-year }\end{array}$} & & 0.0605 & $\star \star$ & 0.0569 & ** & 0.0541 & ** \\
\hline & & $(0.0048)$ & & $(0.0048)$ & & $(0.0046)$ & \\
\hline \multirow[t]{2}{*}{ Part-time, full-year to no job } & & 0.0972 & $\star \star$ & 0.0966 & ** & 0.0916 & ** \\
\hline & & (0.0103) & & $(0.0102)$ & & $(0.0096)$ & \\
\hline \multirow[t]{2}{*}{ Part-time, full-year to part-year } & & 0.0261 & ** & 0.0248 & ** & 0.0358 & ** \\
\hline & & $(0.0062)$ & & $(0.0062)$ & & $(0.0059)$ & \\
\hline \multirow[t]{2}{*}{ Part-year to no job } & & 0.1107 & ** & 0.1099 & ** & 0.1010 & ** \\
\hline & & $(0.0040)$ & & $(0.0039)$ & & $(0.0038)$ & \\
\hline \multirow[t]{2}{*}{ Other work commitment change } & & 0.0295 & $\star \star$ & 0.0281 & ** & 0.0276 & ** \\
\hline & & $(0.0023)$ & & $(0.0023)$ & & $(0.0022)$ & \\
\hline \multirow{2}{*}{$\begin{array}{l}\text { Large employer firm to medium } \\
\text { employer firm }\end{array}$} & & & & 0.0304 & ** & 0.0213 & ** \\
\hline & & & & $(0.0033)$ & & $(0.0031)$ & \\
\hline \multirow{2}{*}{$\begin{array}{l}\text { Large employer firm to small } \\
\text { employer firm }\end{array}$} & & & & 0.0664 & ** & 0.0536 & ** \\
\hline & & & & $(0.0043)$ & & $(0.0040)$ & \\
\hline \multirow{2}{*}{$\begin{array}{l}\text { Large employer firm to very small } \\
\text { employer firm }\end{array}$} & & & & 0.0804 & ** & 0.0700 & ** \\
\hline & & & & $(0.0036)$ & & $(0.0034)$ & \\
\hline \multirow{2}{*}{$\begin{array}{l}\text { Medium employer firm to small } \\
\text { employer firm }\end{array}$} & & & & 0.0666 & ** & 0.0534 & ** \\
\hline & & & & $(0.0053)$ & & $(0.0050)$ & \\
\hline \multirow{2}{*}{$\begin{array}{l}\text { Medium employer firm to very } \\
\text { small employer firm }\end{array}$} & & & & 0.0969 & ** & 0.0851 & ** \\
\hline & & & & $(0.0056)$ & & $(0.0052)$ & \\
\hline \multirow{2}{*}{$\begin{array}{l}\text { Small employer firm to very small } \\
\text { employer firm }\end{array}$} & & & & 0.0684 & ** & 0.0591 & ** \\
\hline & & & & $(0.0052)$ & & $(0.0049)$ & \\
\hline \multirow[t]{2}{*}{ Other employer size change } & & & & 0.0248 & ** & 0.0161 & ** \\
\hline & & & & $(0.0023)$ & & $(0.0021)$ & \\
\hline Demographic controls & No & No & & No & & Yes & \\
\hline Mean of dependent variable & 0.0720 & 0.0720 & & 0.0720 & & 0.0720 & \\
\hline Log Likelihood value & -36147 & -35818 & & -35523 & & -33295 & \\
\hline Sample size & 143,030 & 143,030 & & 143,030 & & 143,030 & \\
\hline
\end{tabular}

Notes: (1) The sample consists of individuals (ages 25-55) who have health insurance in the first survey year. (2) Marginal effects and their standard errors are reported. Statistical significance at the 0.05 and 0.01 levels are denoted by * and **, respectively. (3) All specifications include year effects. Specification 4 also includes controls for sex, race/ethnicity, immigrant status, marital status, number of children, education, age, disability, veteran status, Census divisions, and central city status measured at the first survey date. (4) All estimates are calculated using sample weights provided by the CPS. (5) Employer changes are imputed from changes in industry, employer size and class of worker, and having multiple jobs in the second survey year. 
Table 6

Probit Regressions for Probability of Health Insurance Gain - Marginal Effects Current Population Survey, Matched Annual Demographic Surveys (1996-2004)

\begin{tabular}{|c|c|c|c|c|c|c|c|c|}
\hline \multirow[b]{2}{*}{ Correlated Factor } & \multicolumn{8}{|c|}{ Specification } \\
\hline & \multicolumn{2}{|l|}{$(1)$} & \multicolumn{2}{|l|}{$(2)$} & \multicolumn{2}{|l|}{ (3) } & \multicolumn{2}{|l|}{$(4)$} \\
\hline \multirow[t]{2}{*}{ No job in both years } & -0.0162 & & -0.0237 & * & -0.0482 & ** & -0.0532 & ** \\
\hline & $(0.0106)$ & & (0.0108) & & (0.0107) & & (0.0110) & \\
\hline \multirow[t]{2}{*}{ Job loss } & -0.0186 & & -0.0262 & & -0.0507 & ** & -0.0478 & ** \\
\hline & $(0.0146)$ & & $(0.0147)$ & & $(0.0146)$ & & $(0.0143)$ & \\
\hline \multirow[t]{2}{*}{ No job to job } & 0.0440 & $\star *$ & & & & & & \\
\hline & $(0.0138)$ & & & & & & & \\
\hline \multirow[t]{2}{*}{ Employer size loss } & 0.0451 & ** & 0.0443 & ** & & & & \\
\hline & (0.0100) & & (0.0100) & & & & & \\
\hline \multirow[t]{2}{*}{ Employer size gain } & 0.1088 & $\star \star$ & 0.1071 & ** & & & & \\
\hline & $(0.0095)$ & & $(0.0095)$ & & & & & \\
\hline \multirow{2}{*}{$\begin{array}{l}\text { Self-employment to private } \\
\text { employer }\end{array}$} & -0.0115 & & -0.0093 & & -0.0241 & & -0.0535 & ** \\
\hline & $(0.0168)$ & & $(0.0168)$ & & $(0.0172)$ & & $(0.0168)$ & \\
\hline \multirow{2}{*}{$\begin{array}{l}\text { Private employer to government } \\
\text { employer }\end{array}$} & 0.1952 & ** & 0.1972 & ** & 0.1841 & ** & 0.1301 & ** \\
\hline & $(0.0233)$ & & $(0.0232)$ & & $(0.0233)$ & & $(0.0225)$ & \\
\hline \multirow{2}{*}{$\begin{array}{l}\text { Self-employment to government } \\
\text { employer }\end{array}$} & 0.0831 & & 0.0855 & & 0.0267 & & -0.0485 & \\
\hline & $(0.0631)$ & & $(0.0630)$ & & $(0.0638)$ & & $(0.0620)$ & \\
\hline \multirow[t]{2}{*}{ Other employer type change } & -0.0333 & * & -0.0311 & * & -0.0272 & & -0.0429 & ** \\
\hline & $(0.0159)$ & & $(0.0159)$ & & $(0.0159)$ & & $(0.0154)$ & \\
\hline \multirow[t]{2}{*}{ Employer change } & 0.0552 & ** & 0.0565 & ** & 0.0666 & ** & 0.0617 & ** \\
\hline & (0.0088) & & $(0.0088)$ & & $(0.0088)$ & & $(0.0085)$ & \\
\hline \multirow[t]{2}{*}{ Welfare gain } & 0.6358 & ** & 0.6408 & ** & 0.6419 & ** & 0.6563 & ** \\
\hline & $(0.0435)$ & & $(0.0435)$ & & $(0.0434)$ & & $(0.0420)$ & \\
\hline \multirow[t]{2}{*}{ SSI gain } & 0.7123 & ** & 0.7132 & ** & 0.7133 & ** & 0.7180 & ** \\
\hline & $(0.0468)$ & & $(0.0466)$ & & $(0.0465)$ & & $(0.0447)$ & \\
\hline \multirow[t]{2}{*}{ No children to children } & 0.0941 & ** & 0.0918 & ** & 0.0888 & ** & 0.0848 & ** \\
\hline & $(0.0262)$ & & $(0.0261)$ & & $(0.0262)$ & & $(0.0257)$ & \\
\hline \multirow[t]{2}{*}{ Not married to married } & 0.1658 & ** & 0.1643 & ** & 0.1664 & ** & 0.2256 & ** \\
\hline & $(0.0276)$ & & $(0.0275)$ & & $(0.0275)$ & & $(0.0268)$ & \\
\hline \multirow[t]{2}{*}{ Spousal job gain } & 0.0419 & * & 0.0376 & * & 0.0376 & * & 0.0146 & \\
\hline & $(0.0191)$ & & $(0.0191)$ & & $(0.0191)$ & & (0.0188) & \\
\hline
\end{tabular}

(continued) 
Table 6 (Continued)

\begin{tabular}{|c|c|c|c|c|c|c|c|}
\hline \multirow[b]{2}{*}{ Correlated Factor } & \multicolumn{7}{|c|}{ Specification } \\
\hline & $(1)$ & $(2)$ & & $(3)$ & & $(4)$ & \\
\hline \multirow[t]{2}{*}{ No job to full-time, full-year } & & 0.1376 & ** & 0.1130 & ** & 0.1224 & ** \\
\hline & & $(0.0214)$ & & $(0.0213)$ & & $(0.0208)$ & \\
\hline \multirow[t]{2}{*}{ Part-year to full-time, full-year } & & 0.0233 & * & 0.0243 & * & 0.0291 & ** \\
\hline & & $(0.0116)$ & & $(0.0116)$ & & $(0.0112)$ & \\
\hline \multirow{2}{*}{$\begin{array}{l}\text { Part-time, full-year to full-time, full- } \\
\text { year }\end{array}$} & & 0.0016 & & 0.0006 & & -0.0116 & \\
\hline & & $(0.0200)$ & & $(0.0200)$ & & $(0.0195)$ & \\
\hline \multirow[t]{2}{*}{ No job to part-time, full-year } & & 0.0170 & & -0.0076 & & -0.0221 & \\
\hline & & $(0.0362)$ & & $(0.0362)$ & & $(0.0350)$ & \\
\hline \multirow[t]{2}{*}{ Part-year to part-time, full-year } & & -0.0767 & ** & -0.0753 & ** & -0.0933 & ** \\
\hline & & $(0.0239)$ & & $(0.0239)$ & & $(0.0232)$ & \\
\hline \multirow[t]{2}{*}{ No job to part-year } & & -0.0332 & & -0.0577 & ** & -0.0530 & ** \\
\hline & & $(0.0187)$ & & $(0.0186)$ & & $(0.0182)$ & \\
\hline \multirow[t]{2}{*}{ Other work commitment change } & & -0.0656 & ** & -0.0661 & $\star \star$ & -0.0631 & ** \\
\hline & & $(0.0111)$ & & $(0.0111)$ & & $(0.0107)$ & \\
\hline \multirow{2}{*}{$\begin{array}{l}\text { Medium employer firm to large } \\
\text { employer firm }\end{array}$} & & & & 0.0885 & ** & 0.1119 & ** \\
\hline & & & & $(0.0175)$ & & $(0.0170)$ & \\
\hline \multirow{2}{*}{$\begin{array}{l}\text { Small employer firm to large } \\
\text { employer firm }\end{array}$} & & & & 0.0998 & ** & 0.1058 & ** \\
\hline & & & & $(0.0207)$ & & $(0.0201)$ & \\
\hline \multirow{2}{*}{$\begin{array}{l}\text { Very small employer firm to large } \\
\text { employer firm }\end{array}$} & & & & 0.1437 & ** & 0.1536 & ** \\
\hline & & & & $(0.0169)$ & & $(0.0164)$ & \\
\hline \multirow{2}{*}{$\begin{array}{l}\text { Small employer firm to medium } \\
\text { employer firm }\end{array}$} & & & & -0.0131 & & 0.0313 & \\
\hline & & & & $(0.0252)$ & & $(0.0245)$ & \\
\hline \multirow{2}{*}{$\begin{array}{l}\text { Very small employer firm to } \\
\text { medium employer firm }\end{array}$} & & & & 0.0599 & * & 0.0869 & ** \\
\hline & & & & $(0.0233)$ & & $(0.0226)$ & \\
\hline \multirow{2}{*}{$\begin{array}{l}\text { Very small employer firm to small } \\
\text { employer firm }\end{array}$} & & & & -0.0635 & ** & -0.0295 & \\
\hline & & & & $(0.0199)$ & & $(0.0194)$ & \\
\hline \multirow[t]{2}{*}{ Other employer size change } & & & & -0.0235 & * & -0.0065 & \\
\hline & & & & $(0.0103)$ & & $(0.0100)$ & \\
\hline Demographic controls & No & No & & No & & Yes & \\
\hline Mean of dependent variable & 0.4614 & 0.4614 & & 0.4614 & & 0.4614 & \\
\hline Log Likelihood value & -15302 & -15254 & & -15245 & & -14408 & \\
\hline Sample size & 23,093 & 23,093 & & 23,093 & & 23,093 & \\
\hline
\end{tabular}

Notes: (1) The sample consists of individuals (ages 25-55) who do not have health insurance in the first year surveyed. (2) Marginal effects and their standard errors are reported. Statistical significance at the 0.05 and 0.01 levels are denoted by * and ${ }^{* *}$, respectively. (3) All specifications include year effects. Specification 4 also includes controls for sex, race/ethnicity, immigrant status, marital status, number of children, education, age, disability, veteran status, Census divisions, and central city status measured at the first survey date. (4) All estimates are calculated using sample weights provided by the CPS. (5) Employer changes are imputed from changes in industry, employer size and class of worker, and having multiple jobs in the second survey year. 
Table 7

Decomposition of Racial/Ethnic Gaps in Health Insurance Loss Rates Current Population Survey, Matched Annual Demographic Surveys (1996-2004)

\begin{tabular}{|c|c|c|c|}
\hline Explanatory Variables & Blacks & Latinos & Asians \\
\hline White/minority gap in loss rate & -0.0563 & -0.1023 & -0.0375 \\
\hline \multicolumn{4}{|l|}{ Contributions from racial differences in: } \\
\hline \multirow[t]{3}{*}{ Job loss and other changes } & -0.0170 & -0.0164 & -0.0117 \\
\hline & $(0.0006)$ & $(0.0006)$ & $(0.0005)$ \\
\hline & $30.2 \%$ & $16.0 \%$ & $31.1 \%$ \\
\hline \multirow[t]{3}{*}{ Employer size changes } & 0.0021 & 0.0018 & 0.0015 \\
\hline & $(0.0002)$ & $(0.0002)$ & $(0.0002)$ \\
\hline & $-3.8 \%$ & $-1.7 \%$ & $-3.9 \%$ \\
\hline \multirow[t]{3}{*}{ Employer type changes } & 0.0014 & 0.0016 & 0.0003 \\
\hline & $(0.0001)$ & $(0.0001)$ & $(0.0001)$ \\
\hline & $-2.4 \%$ & $-1.5 \%$ & $-0.7 \%$ \\
\hline \multirow[t]{3}{*}{ Employer change } & 0.0013 & 0.0016 & 0.0002 \\
\hline & $(0.0002)$ & $(0.0002)$ & $(0.0001)$ \\
\hline & $-2.3 \%$ & $-1.5 \%$ & $-0.6 \%$ \\
\hline \multirow[t]{3}{*}{ Welfare or SSI loss } & -0.0044 & -0.0027 & -0.0002 \\
\hline & $(0.0003)$ & $(0.0002)$ & $(0.0001)$ \\
\hline & $7.7 \%$ & $2.7 \%$ & $0.6 \%$ \\
\hline \multirow[t]{3}{*}{ Changes in family characteristics } & 0.0001 & -0.0009 & -0.0011 \\
\hline & $(0.0000)$ & $(0.0001)$ & $(0.0001)$ \\
\hline & $-0.2 \%$ & $0.9 \%$ & $2.8 \%$ \\
\hline \multirow[t]{3}{*}{ Education level } & -0.0085 & -0.0176 & 0.0035 \\
\hline & $(0.0003)$ & $(0.0008)$ & $(0.0002)$ \\
\hline & $15.1 \%$ & $17.2 \%$ & $-9.3 \%$ \\
\hline \multirow[t]{3}{*}{ Demographic characteristics } & -0.0062 & 0.0045 & 0.0057 \\
\hline & $(0.0011)$ & $(0.0009)$ & $(0.0009)$ \\
\hline & $11.0 \%$ & $-4.4 \%$ & $-15.2 \%$ \\
\hline \multirow[t]{3}{*}{ Year effects } & 0.0004 & 0.0003 & 0.0003 \\
\hline & $(0.0001)$ & $(0.0001)$ & $(0.0001)$ \\
\hline & $-0.8 \%$ & $-0.3 \%$ & $-0.7 \%$ \\
\hline All included variables ("explained" & -0.0307 & -0.0278 & -0.0015 \\
\hline part of the gap) & $54.6 \%$ & $27.2 \%$ & $4.1 \%$ \\
\hline
\end{tabular}

Notes: (1) The sample consists of individuals (ages 25-55) who have health insurance in the first survey year. (2) Demographic characteristics include sex, marital status, number of children, age, disability, veteran status, Census divisions, and central city status measured at the first survey date (3) Contribution estimates are means values of non-linear decompositions using 1,000 subsamples of whites. Standard errors are reported in parentheses below contribution estimates. See text for more details. 
Table 8

Decomposition of Racial/Ethnic Gaps in Health Insurance Gain Rates Current Population Survey, Matched Annual Demographic Surveys (1996-2004)

\begin{tabular}{|c|c|c|c|}
\hline Explanatory Variables & Blacks & Latinos & Asians \\
\hline White/minority gap in gain rate & -0.0027 & 0.1600 & -0.0115 \\
\hline \multicolumn{4}{|l|}{ Contributions from racial differences in: } \\
\hline \multirow[t]{3}{*}{ Job gain and other changes } & -0.0005 & 0.0001 & -0.0003 \\
\hline & $(0.0008)$ & $(0.0006)$ & $(0.0008)$ \\
\hline & & $0.0 \%$ & \\
\hline \multirow[t]{3}{*}{ Employer size changes } & -0.0033 & -0.0045 & 0.0011 \\
\hline & $(0.0003)$ & $(0.0003)$ & $(0.0002)$ \\
\hline & & $-2.8 \%$ & \\
\hline \multirow[t]{3}{*}{ Employer type changes } & -0.0036 & -0.0006 & 0.0007 \\
\hline & $(0.0006)$ & $(0.0006)$ & $(0.0003)$ \\
\hline & & $-0.4 \%$ & \\
\hline \multirow[t]{3}{*}{ Employer change } & 0.0012 & 0.0026 & 0.0031 \\
\hline & $(0.0002)$ & $(0.0005)$ & $(0.0006)$ \\
\hline & & $1.6 \%$ & \\
\hline \multirow[t]{3}{*}{ Welfare or SSI loss } & -0.0093 & 0.0005 & 0.0024 \\
\hline & $(0.0002)$ & $(0.0001)$ & $(0.0001)$ \\
\hline & & $0.3 \%$ & \\
\hline \multirow[t]{3}{*}{ Changes in family characteristics } & -0.0001 & 0.0005 & 0.0000 \\
\hline & $(0.0002)$ & $(0.0003)$ & $(0.0005)$ \\
\hline & & $0.3 \%$ & \\
\hline \multirow[t]{3}{*}{ Education level } & 0.0113 & 0.0486 & -0.0167 \\
\hline & $(0.0007)$ & $(0.0031)$ & $(0.0015)$ \\
\hline & & $30.4 \%$ & \\
\hline \multirow[t]{3}{*}{ Demographic characteristics } & 0.0221 & -0.0049 & -0.0250 \\
\hline & $(0.0039)$ & $(0.0042)$ & $(0.0048)$ \\
\hline & & $-3.1 \%$ & \\
\hline \multirow[t]{3}{*}{ Year effects } & 0.0008 & -0.0001 & 0.0008 \\
\hline & $(0.0003)$ & $(0.0005)$ & $(0.0006)$ \\
\hline & & $-0.1 \%$ & \\
\hline \multirow{2}{*}{$\begin{array}{l}\text { All included variables ("explained" } \\
\text { part of the gap) }\end{array}$} & 0.0186 & 0.0422 & -0.0339 \\
\hline & & $26.3 \%$ & \\
\hline
\end{tabular}

Notes: (1) The sample consists of individuals (ages 25-55) who do not have health insurance in the first survey year. (2) Demographic characteristics include sex, marital status, number of children, age, disability, veteran status, Census divisions, and central city status measured at the first survey date. (3) Contribution estimates are means values of non-linear decompositions using 1,000 subsamples of whites. Standard errors are reported in parentheses below contribution estimates. See text for more details. 
Appendix 1

Means of Analysis Variables for Health Insurance Loss Regressions by Race Current Population Survey, Matched Annual Demographic Surveys (1996-2004)

\begin{tabular}{lcccc} 
& White & Black & Latino & Asian \\
\hline No job in both years & 0.0907 & 0.1295 & 0.1383 & 0.1071 \\
Job loss & 0.0298 & 0.0446 & 0.0411 & 0.0387 \\
No job to job & 0.0211 & 0.0312 & 0.0378 & 0.0297 \\
Employer size loss & 0.1758 & 0.1910 & 0.1933 & 0.1845 \\
Employer size gain & 0.1703 & 0.1673 & 0.1864 & 0.1714 \\
Private employer to self- & & & & \\
employment & 0.0230 & 0.0113 & 0.0142 & 0.0243 \\
Government employer to private & & & & \\
employer & 0.0211 & 0.0447 & 0.0265 & 0.0231 \\
Government employer to self- & & & & \\
employment & 0.0019 & 0.0018 & 0.0018 & 0.0017 \\
Other employer type change & 0.0449 & 0.0524 & 0.0339 & 0.0470 \\
Employer change & 0.3834 & 0.4174 & 0.3929 & 0.4133 \\
Welfare loss & 0.0046 & 0.0269 & 0.0230 & 0.0085 \\
SSI loss & 0.0062 & 0.0210 & 0.0112 & 0.0049 \\
Children to no children & 0.0266 & 0.0280 & 0.0212 & 0.0265 \\
Married to not married & 0.0092 & 0.0114 & 0.0112 & 0.0097 \\
Spousal job loss & 0.0241 & 0.0226 & 0.0303 & 0.0301 \\
High school dropout & 0.0555 & 0.1275 & 0.3091 & 0.0852 \\
High school graduate & 0.3172 & 0.3555 & 0.3002 & 0.2022 \\
Some college & 0.2845 & 0.3190 & 0.2315 & 0.2052 \\
Sample size & 115,059 & 12,002 & 9,102 & 5,123 \\
\hline Notes:(1) & & & &
\end{tabular}

Notes: (1) The sample consists of individuals (ages 25-55) who have health insurance in the first year surveyed. (2) All estimates are calculated using sample weights provided by the CPS. 
Appendix 2

Probit Regressions for Probability of Health Insurance Gain or Loss - Marginal Effects Current Population Survey, Matched Annual Demographic Surveys (1996-2004)

\begin{tabular}{|c|c|c|c|c|}
\hline & & peci & ation & \\
\hline Correlated Factor & Loss & & Gain & \\
\hline No job in both years & 0.0439 & ** & -0.0226 & * \\
\hline & $(0.0026)$ & & $(0.0109)$ & \\
\hline Job loss & 0.1075 & ** & -0.0150 & \\
\hline & $(0.0030)$ & & $(0.0143)$ & \\
\hline No job to job & 0.0839 & ** & 0.0457 & ** \\
\hline & $(0.0036)$ & & $(0.0136)$ & \\
\hline Employer size loss & 0.0341 & ** & 0.0578 & ** \\
\hline & $(0.0018)$ & & $(0.0098)$ & \\
\hline Employer size gain & 0.0028 & & 0.1265 & ** \\
\hline & $(0.0020)$ & & $(0.0093)$ & \\
\hline Private employer to self-employment / self-employment & 0.0540 & ** & -0.0428 & ** \\
\hline to private employer & $(0.0037)$ & & $(0.0164)$ & \\
\hline Government employer to private employer / private & 0.0098 & * & 0.1412 & ** \\
\hline employer to government employer & $(0.0039)$ & & $(0.0225)$ & \\
\hline Government employer to self-employment / self- & 0.0668 & ** & 0.0090 & \\
\hline employment to government employer & $(0.0109)$ & & $(0.0614)$ & \\
\hline Other employer type change & 0.0181 & ** & -0.0479 & ** \\
\hline & $(0.0031)$ & & $(0.0154)$ & \\
\hline Employer change & 0.0316 & ** & 0.0492 & ** \\
\hline & $(0.0017)$ & & $(0.0086)$ & \\
\hline Welfare loss / welfare gain & 0.0575 & ** & 0.6603 & ** \\
\hline & $(0.0050)$ & & $(0.0421)$ & \\
\hline SSI loss / SSI gain & 0.0446 & ** & 0.7218 & ** \\
\hline & $(0.0055)$ & & $(0.0450)$ & \\
\hline Children to no children / no children to children & 0.0019 & & 0.0815 & ** \\
\hline & $(0.0042)$ & & $(0.0257)$ & \\
\hline Married to not married / not married to married & 0.0545 & ** & 0.2212 & ** \\
\hline & $(0.0055)$ & & $(0.0268)$ & \\
\hline Spousal job loss / spousal job gain & 0.0549 & ** & 0.0143 & \\
\hline & $(0.0035)$ & & $(0.0189)$ & \\
\hline
\end{tabular}

(continued) 
Appendix 2 (Continued)

\begin{tabular}{|c|c|c|c|c|}
\hline \multirow[b]{2}{*}{ Correlated Factor } & \multicolumn{4}{|c|}{ Specification } \\
\hline & Loss & & Gain & \\
\hline \multirow[t]{2}{*}{ High school dropout } & 0.0767 & 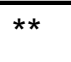 & -0.1893 & ** \\
\hline & $(0.0024)$ & & $(0.0113)$ & \\
\hline \multirow[t]{2}{*}{ High school graduate } & 0.0487 & ** & -0.1113 & ** \\
\hline & $(0.0018)$ & & $(0.0101)$ & \\
\hline \multirow[t]{2}{*}{ Some college } & 0.0293 & ** & -0.0563 & ** \\
\hline & $(0.0019)$ & & $(0.0108)$ & \\
\hline \multirow[t]{2}{*}{ Black } & 0.0207 & ** & 0.0121 & \\
\hline & $(0.0020)$ & & $(0.0097)$ & \\
\hline \multirow[t]{2}{*}{ Latino } & 0.0499 & ** & -0.1264 & ** \\
\hline & $(0.0022)$ & & $(0.0094)$ & \\
\hline \multirow[t]{2}{*}{ Asian } & 0.0433 & ** & -0.0371 & * \\
\hline & $(0.0032)$ & & $(0.0149)$ & \\
\hline \multirow[t]{2}{*}{ Native American } & 0.0423 & ** & -0.0769 & ** \\
\hline & $(0.0062)$ & & $(0.0288)$ & \\
\hline \multirow[t]{2}{*}{ Multiple Races } & -0.0168 & & 0.0489 & \\
\hline & $(0.0164)$ & & $(0.0668)$ & \\
\hline Demographic controls & Yes & & Yes & \\
\hline Mean of dependent variable & 0.0720 & & 0.4614 & \\
\hline Log Likelihood value & -33967 & & -14493 & \\
\hline Sample size & 143,030 & & 23,093 & \\
\hline
\end{tabular}

Notes: (1) The sample consists of individuals (ages 25-55) who have (Specification 1) and do not have (Specification 2) health insurance in the first year surveyed. (2) Marginal effects and their standard errors are reported. Statistical significance at the 0.05 and 0.01 levels are denoted by * and ${ }^{*}$, respectively. (3) All specifications include year effects, and controls for sex, marital status, number of children, age, disability, veteran status, Census divisions, and central city status measured at the first survey date. (4) All estimates are calculated using sample weights provided by the CPS. (5) Employer changes are imputed from changes in industry, employer size and class of worker, and having multiple jobs in the second survey year. 
Appendix 3

Means of Analysis Variables for Health Insurance Gain Regressions by Race Current Population Survey, Matched Annual Demographic Surveys (1996-2004)

\begin{tabular}{|c|c|c|c|c|}
\hline & White & Black & Latino & Asian \\
\hline No job in both years & 0.1309 & 0.1642 & 0.1694 & 0.1783 \\
\hline Job loss & 0.0596 & 0.0893 & 0.0543 & 0.0637 \\
\hline No job to job & 0.0600 & 0.0781 & 0.0714 & 0.0792 \\
\hline Employer size loss & 0.1612 & 0.1677 & 0.1746 & 0.1567 \\
\hline Employer size gain & 0.2003 & 0.2259 & 0.2230 & 0.2048 \\
\hline $\begin{array}{l}\text { Self-employment to private } \\
\text { employer }\end{array}$ & 0.0520 & 0.0203 & 0.0281 & 0.0460 \\
\hline $\begin{array}{l}\text { Private employer to government } \\
\text { employer }\end{array}$ & 0.0223 & 0.0421 & 0.0127 & 0.0188 \\
\hline $\begin{array}{l}\text { Self-employment to government } \\
\text { employer }\end{array}$ & 0.0031 & 0.0034 & 0.0013 & 0.0012 \\
\hline Other employer type change & 0.0541 & 0.0404 & 0.0348 & 0.0487 \\
\hline Employer change & 0.4334 & 0.4230 & 0.3842 & 0.3812 \\
\hline Welfare gain & 0.0095 & 0.0250 & 0.0133 & 0.0084 \\
\hline SSI gain & 0.0128 & 0.0229 & 0.0080 & 0.0073 \\
\hline No children to children & 0.0137 & 0.0157 & 0.0159 & 0.0333 \\
\hline Not married to married & 0.0160 & 0.0128 & 0.0116 & 0.0091 \\
\hline Spousal job gain & 0.0254 & 0.0209 & 0.0388 & 0.0349 \\
\hline High school dropout & 0.1618 & 0.2370 & 0.5570 & 0.1513 \\
\hline High school graduate & 0.4208 & 0.4285 & 0.2552 & 0.3136 \\
\hline Some college & 0.2594 & 0.2447 & 0.1366 & 0.2195 \\
\hline Sample size & 14,171 & 2,824 & 4,450 & 1,055 \\
\hline
\end{tabular}

Notes: (1) The sample consists of individuals (ages 25-55) who do not have health insurance in the first year surveyed. (2) All estimates are calculated using sample weights provided by the CPS. 